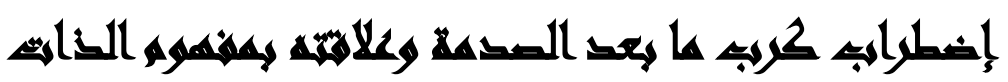

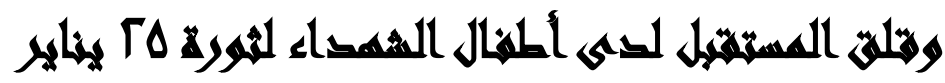

مروة شحاتة ابراهيم عبد الحكيم(')- جمال شفيق أحمد(؟)- الفرحاتى السيد فرحاتي(") حنان السيد زيدان(

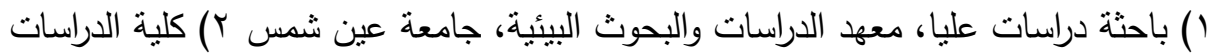

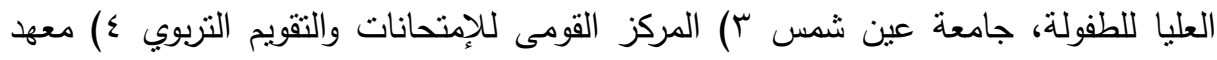

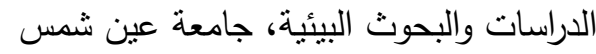

\title{
المستخلئ
}

هدف البحث إلى معرفة إضطراب كرب مابعد الصدمة وعلاقتة بمفهوم الذات وقلق وإنق

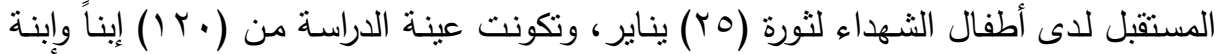

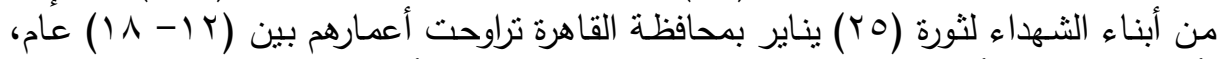

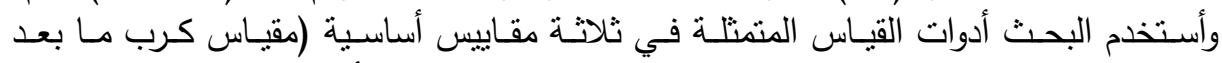

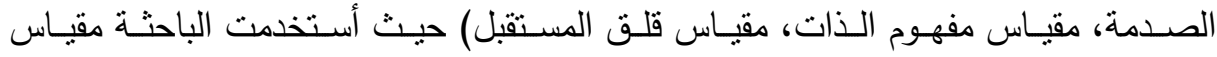

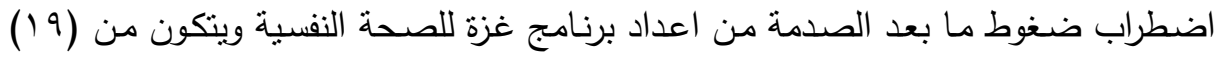
عبارة.

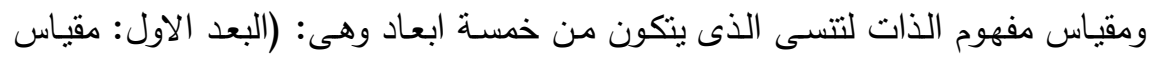

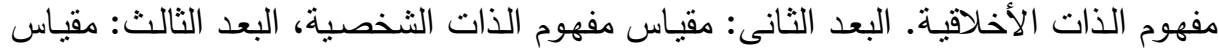

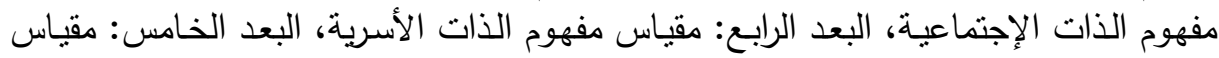

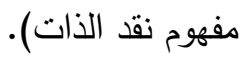
مقياس قلق المستقبل من اعداد غالب المشيخى (9 . . †) والذى يتكون من خمس ابعاد

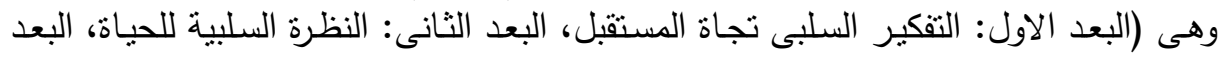

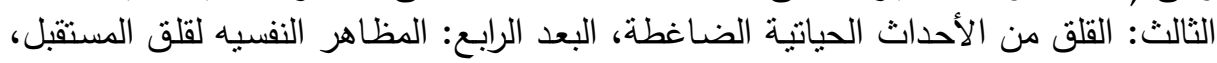
البعد الخامس: المظاهر الجسمية لقلق المستقبل ).

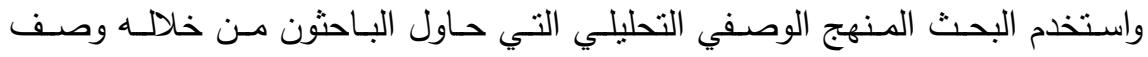

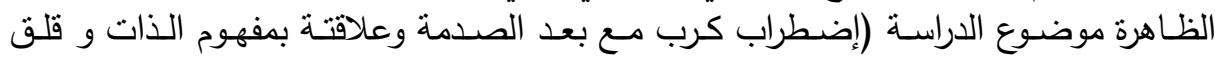

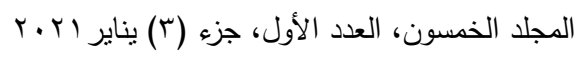

$$
\begin{aligned}
& \text { النزقيم الدولي 0826-1110 1SSN }
\end{aligned}
$$


المستقبل لاى أطفال الثهداء لثورة (Yo) يناير) وتحليل بياناتها وبيان العلاقة بين مكوناتها

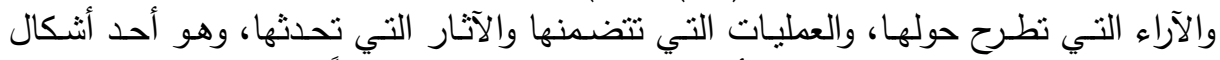

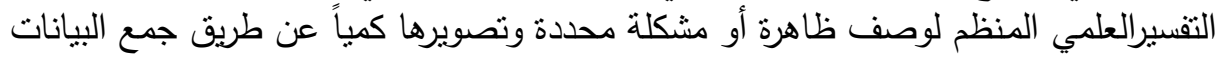
والمعلومات المقننة عن الظاهرة أو المشكلة وتصنيفها وتحليلها واخضاعها للإراسات الدقيقة.

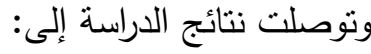

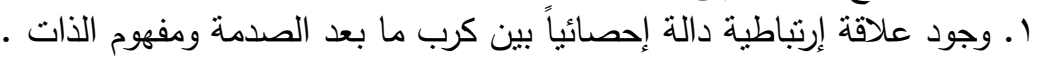

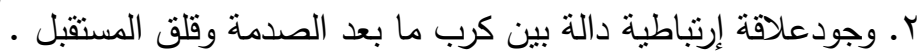

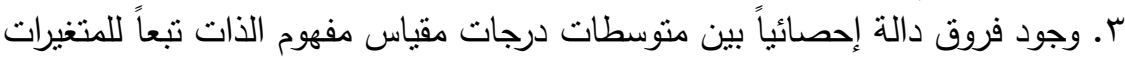

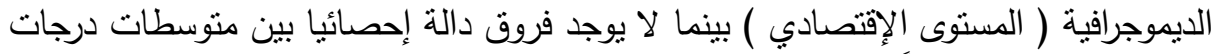

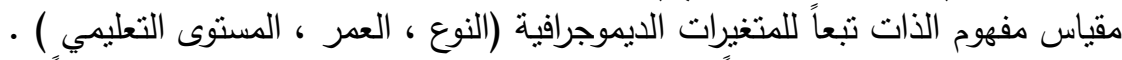

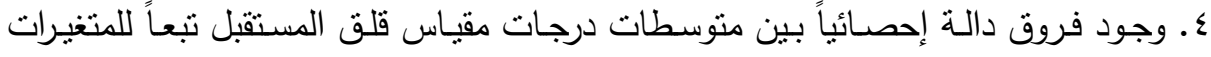

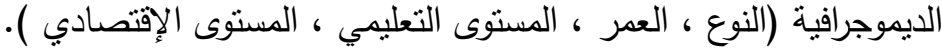

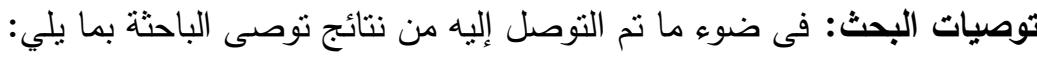

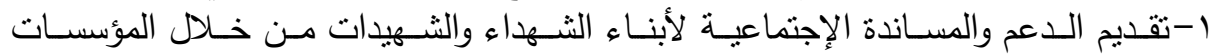
الإجتماعية والوسائل الإعلامية للتخفيف من أعراض الصدمه والمشكلات النفسية المرنبطة الإنة بها. r-صياغة برامج إرشادية لتحقيق التكيف النفسي والإجتماعي ، وبناء مفهوم ذات سوي لاى

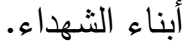

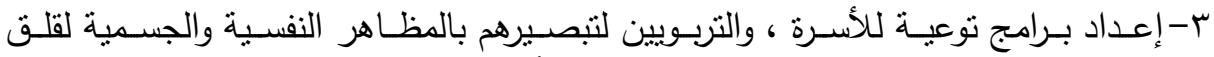

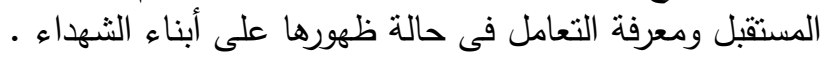

ع-وضع برامج علاجية للتخفيف من النظرة السلبية للحياة التي يعاني منهاء أبناء الثهاء النهاء ـ النهاء

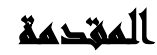

تشكل الأحداث الضـاغطة والتى هى أحد أشثكال المثيرات الضـاغطة التى يتعرض لها الفرد خطراً كبيراً على صحة الفرد وتوازنه، وتهدد صحته النفسية لما لها من آثار سلبية، وتسبب له شعوراً بالضغوط أو العصاب والتى تتباين من بيئة لأخرى ومن فرد لآخر ، وتعد وند الحروب والأزمات والكوارث من العوامل المسببة للضغوط النفسية وقد تحدث تأثيرات تفوق تأثنيرات أحداث الحياة الضـاغطة ويعود ذلك إلى عدم وجود خبرات ممانلـة لدى الفرد فى لـى 230

$$
\begin{aligned}
& \text { المجلد الخمسون، العدد الأول، جزء (r) يناير آT.r. } \\
& \text { التزقيم الدولي 0826-1110 1SSN }
\end{aligned}
$$




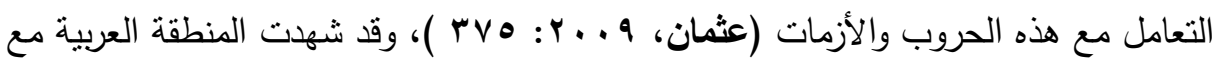

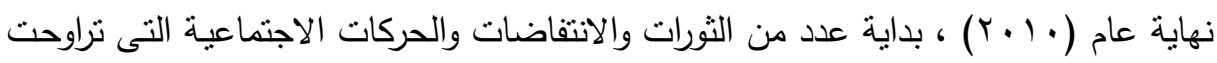

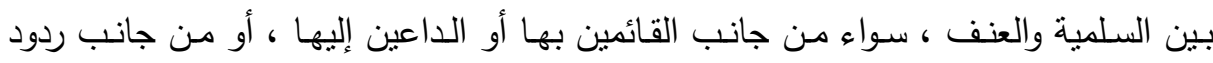

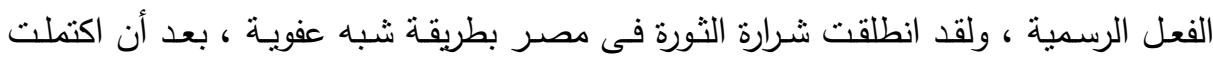

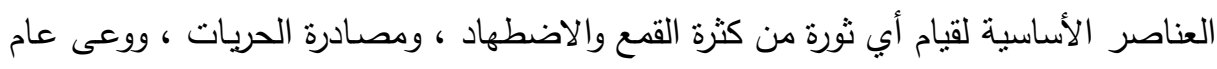

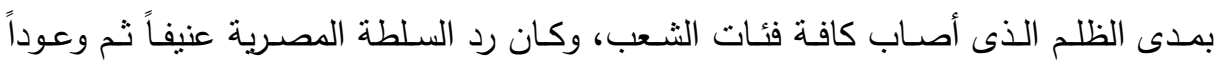

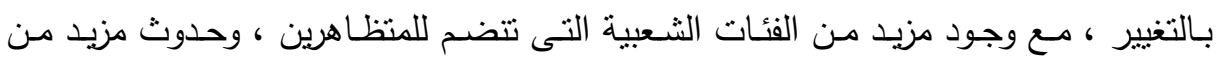

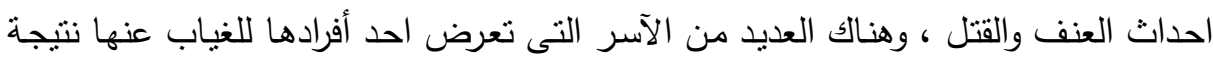

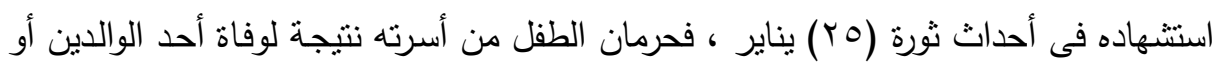

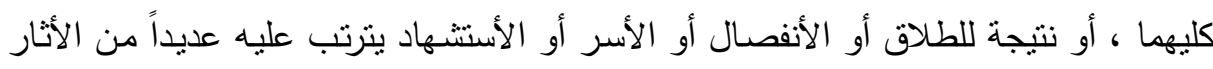

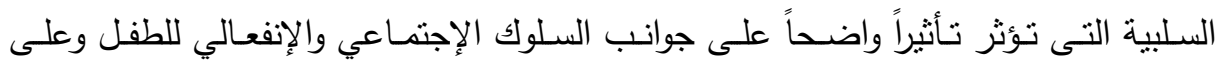
مفهومه الإيجابي عن ذاته ، الذى قد ينأثر بهذا الحرمان ، فيتكون لدى (الطفل - المراهق)

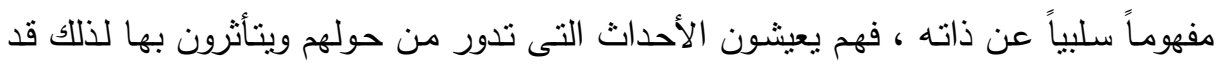

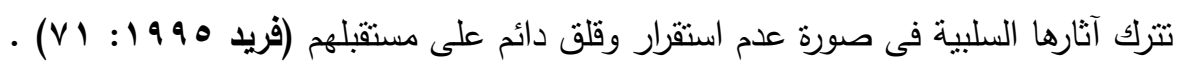

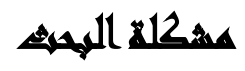

تركز الدراسة الحالية على فقدان أحد أفراد الأسرة نتيجة أحداث ثورة (Yo) يناير ، حيث

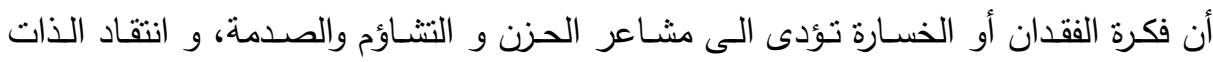

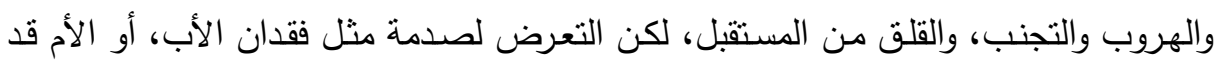

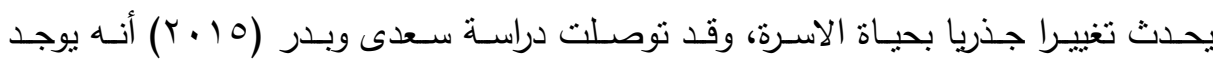

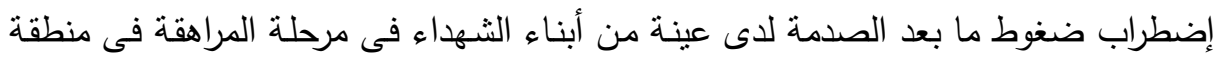

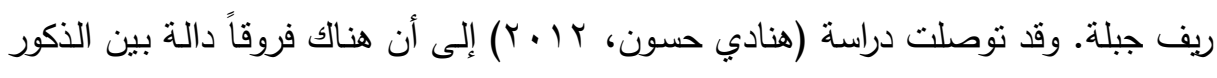

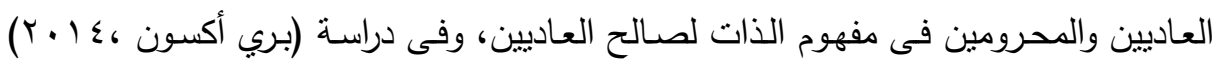

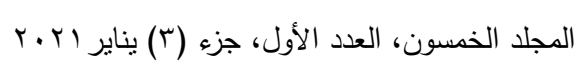

$$
\begin{aligned}
& \text { التزقيم الدولي 0826-1110 1SSN }
\end{aligned}
$$




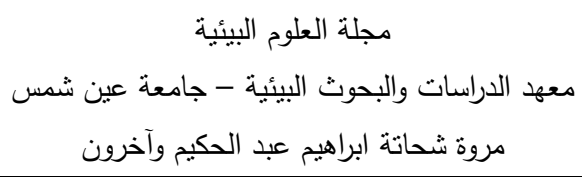

(Bree Akesson ) (أن الأطفال الذين يعيشون فى سياق العنف السياسي يعانون من التوترات والعنف وفقدان الأمل فى المستقبل وعدم الأمن النفسي.

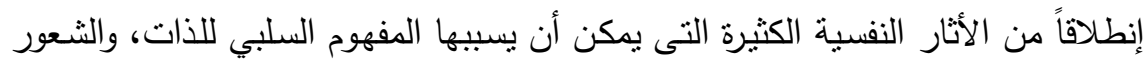

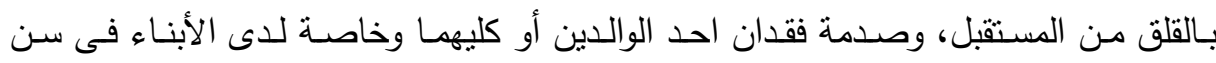

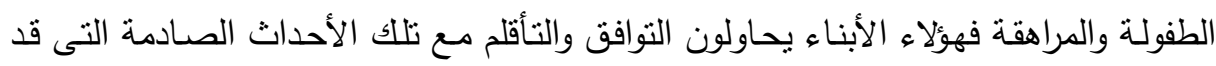

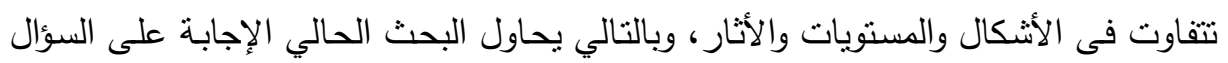

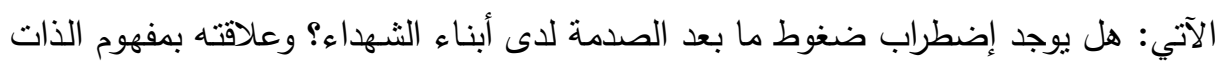

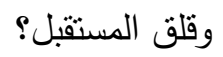

\section{أسرئل المهثم}

ا - ما مدى تأثير إضطراب ضغوط كرب ما بعد الصدمة لأطفال الثهداء لثورة (Yo) يناير؟

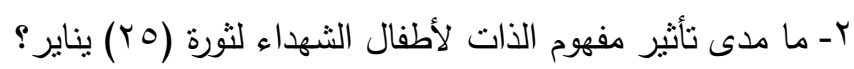

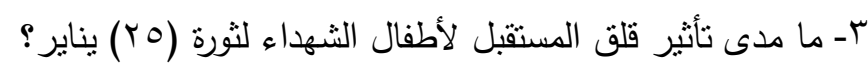

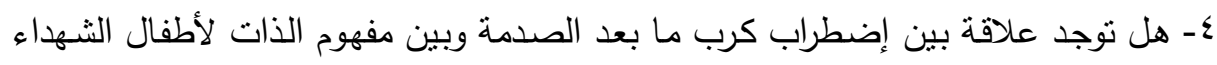

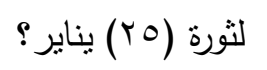

\section{هونه المهيم}

هدفت الدراسة الحالية إلى: معرفة تأثثر كرب ما بعد الصدمة وعلاقتة بمفهوم الذات وقلق

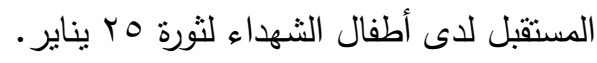

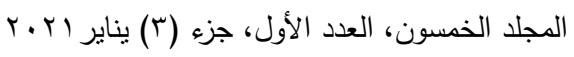

$$
\begin{aligned}
& \text { الترقيم الدولي 0826-0SN 1110 }
\end{aligned}
$$


أهميز المهمث

الأهمية النظرية:

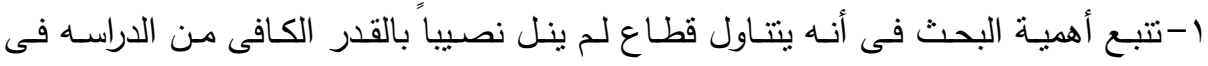
مجتمعنا المصرى وهو قطاع (أسر الثهداء) .

ץ-تبرز أهمية البحث فى كونها تتتاول كرب ما بعد الصدمه ومفهوم الذات وقلق المستقبل حيث يؤثر كلا منهم فى مختلف جوانب حياة الفرد الثخصية والنفسية والسلوكية . r-تتبع أهمية البحث أيضاً من كونها نركز على نخبة من المراهقين وهم عماد المستقبل يؤمل

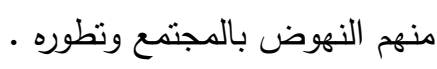

الأهمية التطبيقية :

1-تكمن اهمية البحث فى الكثف عن مستوى كرب ما بعد الصدمه ومستوى مفهوم الذات ودرجة القلق من المستقبل لدى المراهقين ، حتى يمكن أن يوفر للجهات التتفيذية والمربين

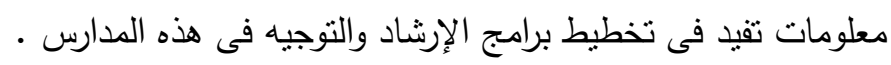

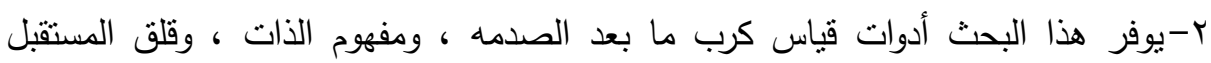
بالمدارس.

\section{Anall}

1- إضطراب كرب ما بعد الصدمة Post Traumatic Stress Disorder: التعريف إصطلاحا: يقدم الدليل التشخيصي والإحصائي الرابع (DSM-IV-) استتاداً إلى الرابطة الأمريكية للطب النفسي تعريفاً للاضطراب على النحو الأتى: إنه فئة من فئات

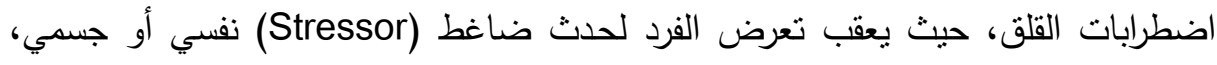
غير عادي، في بعض الأحيان بعد التعرض لله مباشرة، وفي أحيان أخرى ليس قبل ثلاثة

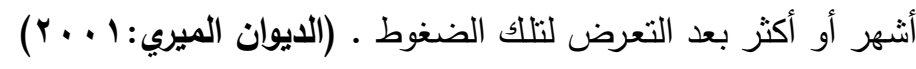

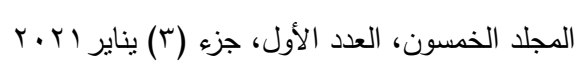

$$
\begin{aligned}
& \text { النزقيم الدولي 0826-1110 1SSN }
\end{aligned}
$$


التعريف إجرائيا: مجموع الدرجات التي يحصل عليها المفحوص على مقياس اضطراب ضغوط ما بعد الصدمة المستخدم لهذه الدراسة والمعد من قبل برنامج غزة للصحة النفسية.

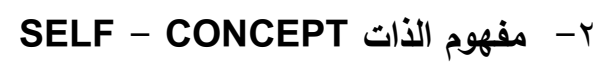
التعريـف إصـلاحا: يعرف مفهوم الذات لفرد مـا، بأنـه تكوين معرفى منظم موحد ومتعلم

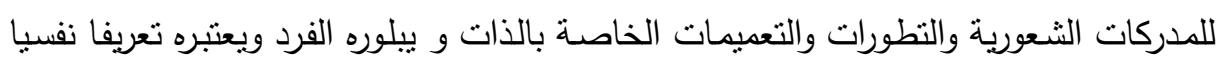
لذاته _ كما أنه يحدد ويعتبره تعريفا نفسيا لذاته _ كما أنه يحدد إنجاز المرء الفعلى و يظهر

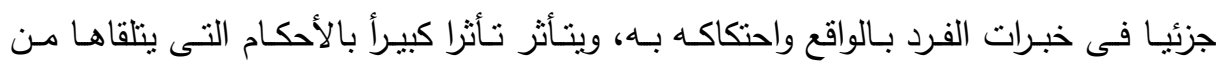

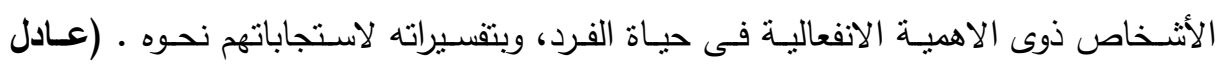

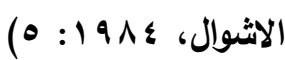
التعريف إجرائيا: مجموع الدرجات التى يحصل عليها المفحوص على مقياس مفهوم الذات

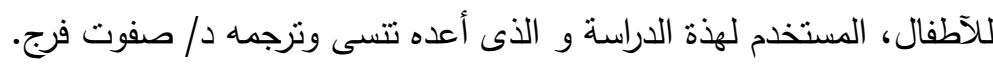
r- قلق المستقبل Future anxiety: التعريف إصطلاحا: هو إضطراب نفسى ناتج عن حالة خوف من المستقبل لأسباب ظاهرة أو مجهولة، تجعل من صاحبها فى حالة من التوتر أو السلبية أو العجز تجاه الواقع و تحدياته على المستوبين الفردى و الجماعى. التعريف إجرائياً: مجموع الدرجات التى يحصل عليها المفحوص على مقياس قلق المستقبل المستخدم لهذة الدراسة والذى أعده غالب المشيخى (9 . . ب). ع - أبناء الشهراء:_هم الذين فقدوا أبويهم فى ويلات الحروب والثثرات، فالثهيد فى اللغة اعنة

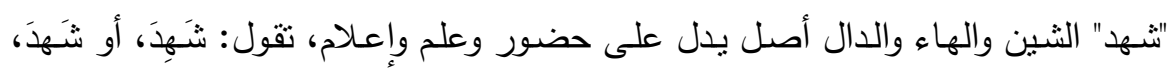

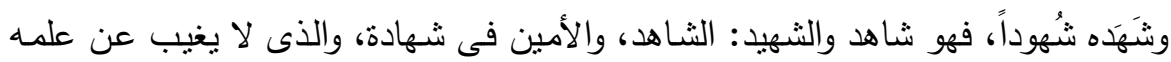

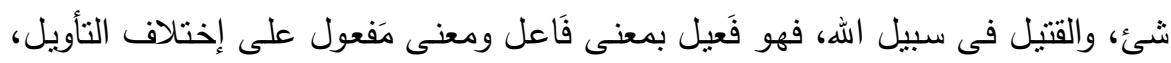

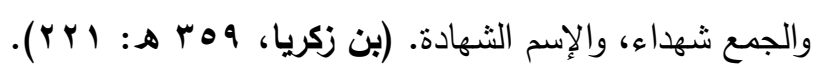

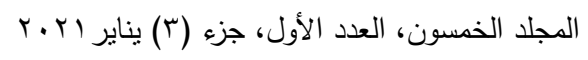

$$
\begin{aligned}
& \text { التزقيم الدولي 0826- ISSN 1110 بناير الإن }
\end{aligned}
$$


ه-مفهوم الثـورة: الثورة هى أسلوب من أسـاليب التغيير الإجتمـاعي، تشـل الاوضـاع السياسية والإجتماعية والإقتصـادية، حيث هي عملية تغيير لا تتبع الوسائل المعتمدة فى الإسى النظام القديم للدولة وتكون جذريـة وشاملة، تؤدى إلى إنهيار النظام القائم وصعود نظام جديد، ويترتب على نجاح الثورة سقوط الدستور وإنهيار النظام الحكومي القائم ولكن لا لا تمس شخصية الدولـة ومؤسسـاتها فى مختلف المجـالات، ولا تؤدى إلى إنهاء العهل بالتشريعات السابقة عليها بطريقة فوضوية، وخاصـة الإيجابية منها وذات الصلة بالحياة العامة فليست كل ما فى النظام القديم هو بالي ويستحق السحق والإبادة، فهذا نوع من ونات

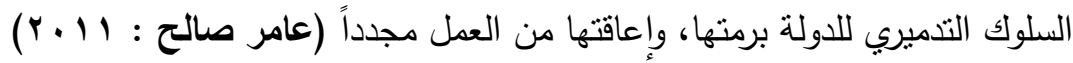

\section{السواساهي الماريه}

المحور الاول: دراسات متعلقة بإضطراب كرب ما بعد الصدمة:

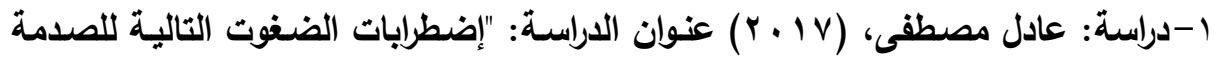

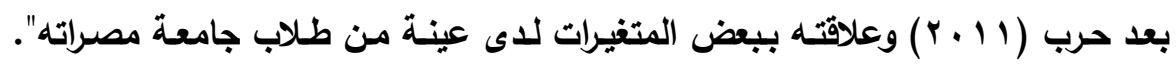

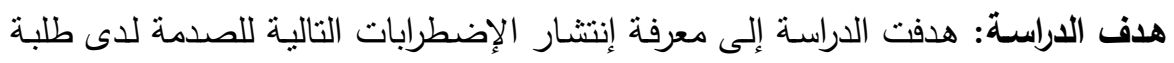

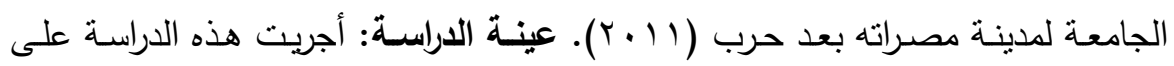

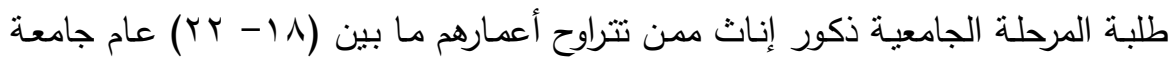

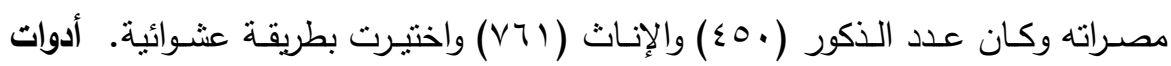

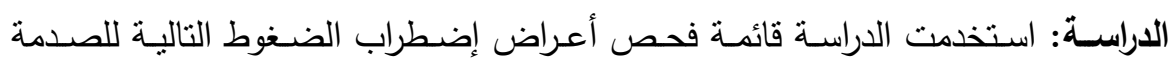
(The PTS Checkist pcl) الحالات التى تعانى من إضطراب الضغوط التالية للصدمة من النوع المتوسط لدى أفراع

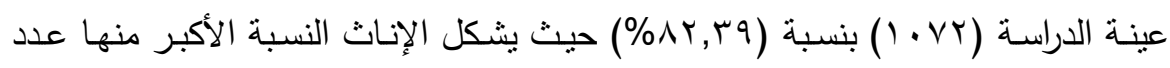
الأفراد التى نعاني من إضطراب ضغوط ما بعد الصدمة من النوع الثديد لدى أفراد العينة

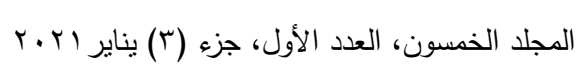

$$
\begin{aligned}
& \text { الترقيم الدولي 0826-1110 }
\end{aligned}
$$




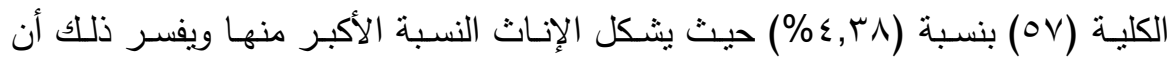
الدراسة الحالية قد تمت بعد مدة زمنية طويلة من أحداث الحرب، ووفقا لما جاء فى الدليل الدابل

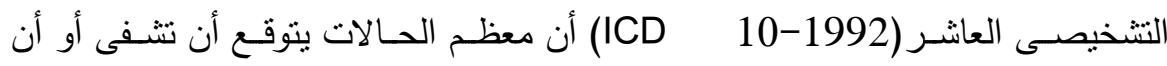
الاعراض قد تظهر لدى البعض بعد أيام او اسابيع أو تظهر لاى البعض بعد عدة أثشهر ،

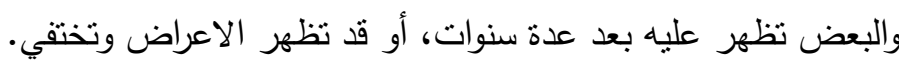

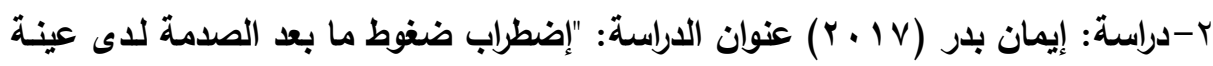

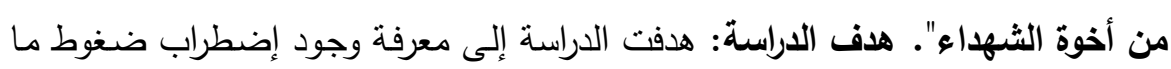

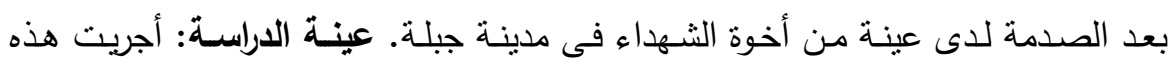

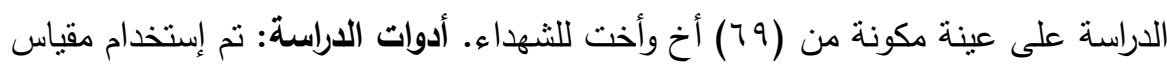

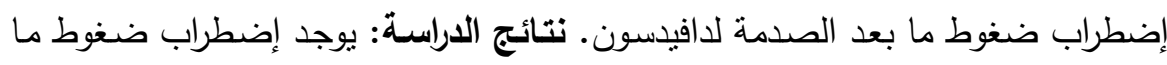

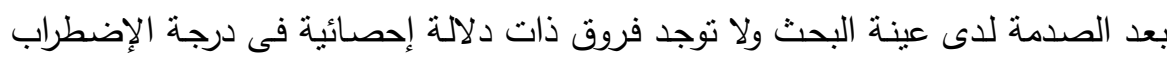
تبعا لمتغييرى الجنس والمستوى التعليمي للعينة، بينما وجدت فروق ذات دلاتلة إحصائلة دائية

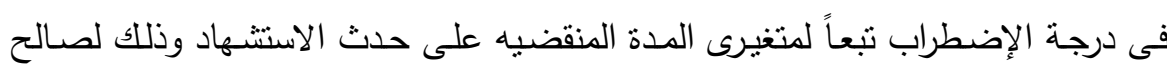

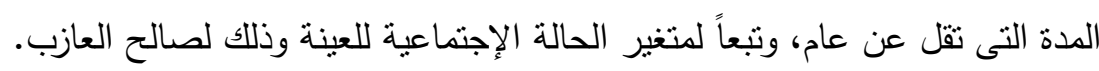

\section{المحور الثانى: دراسات متعلقة بمفهوم الأات:}

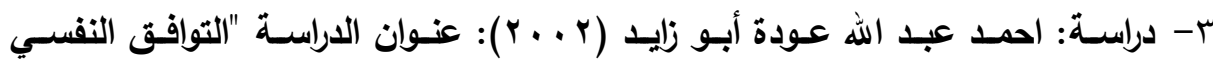
وعلاقته بمفهوم الذات لأبناء شـهـاء وأسرى الانتفاضـة". عينـة الدراسـة: وكانت عينة

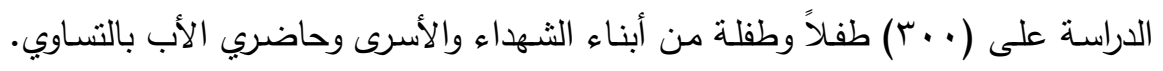

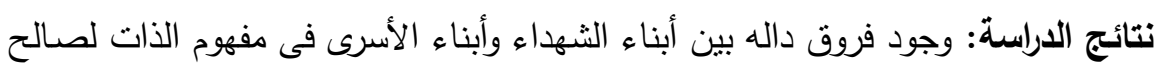

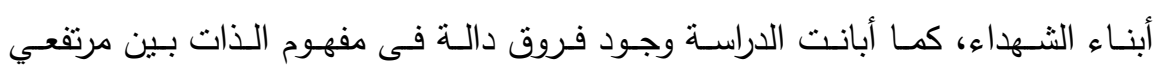

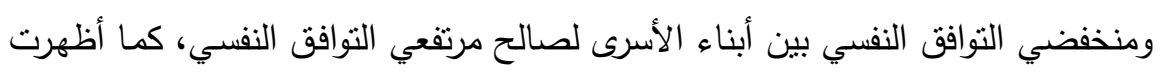

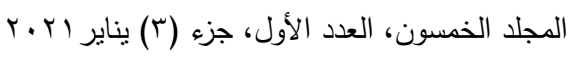

$$
\begin{aligned}
& \text { الترقيم الدولي 0826- ISSN 1110 }
\end{aligned}
$$


نتائج الدراسة وجود فروق داله بين أبناء الثهداء الذكور والإناث فى مفهوم الذات بأبعاده لصالح الإناث عدا البعد الاجتماعي والبعد الجسمي.

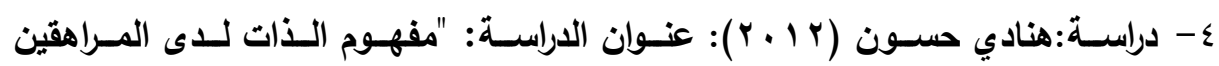

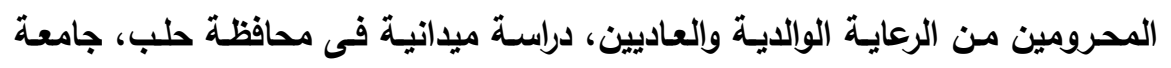
دمشت - كليـة تربيـة". هدف الدراسـة: هدفت الدراسـة إلى المقارنـة بين مجموعة من

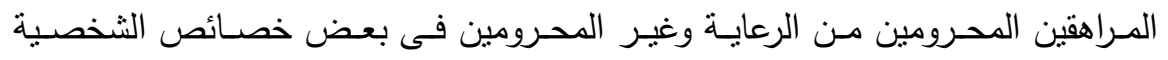

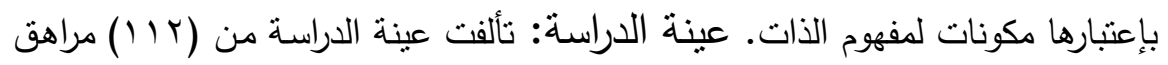

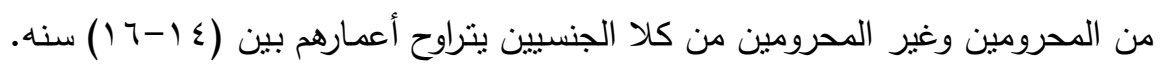
أدوات الداسة: أستخدمت الباحثة فى هذه الدراسة المنهج الوصفي وكذللك مقياس مفهوم

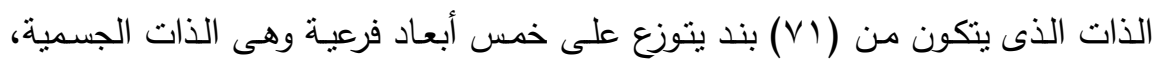
الذات الأخلاقية، الذات الأسرية، الذات الثخصية، الذات الاجتماعية. نتائج الاراسـة:

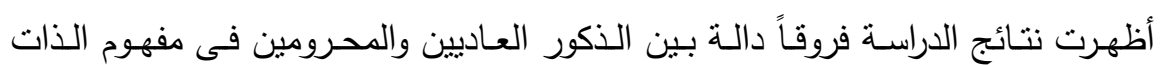
لصالح العاديين فى جميع أبعاد المقياس. المحور الثالث: دراسات متعلقة بقلث المستقبل: ه- آن كونلى (2001 - Conley): عنوان الدراسـة: "دراسـة لاستكشـاف العلاقة بين أعراض الصدمة، التوجه المستقبلي، العدوان/الانحراف لاى المراهقين". هدف الدراسـة:

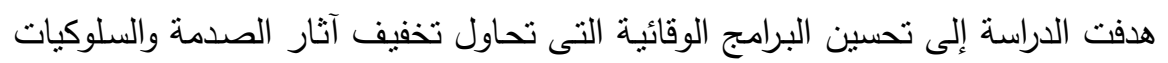

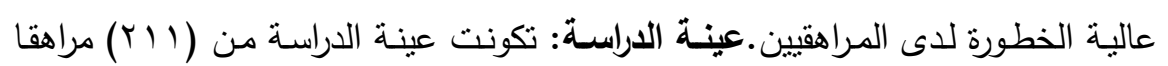

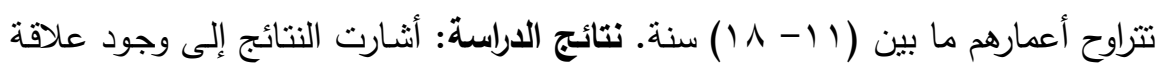

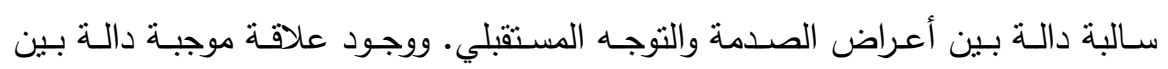

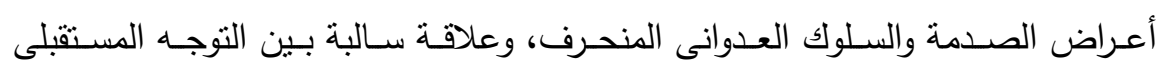

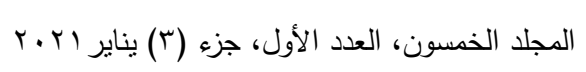

$$
\begin{aligned}
& \text { التزقيم الدولي 0826- ISSN 1110 }
\end{aligned}
$$


والسلوك العدوانى، واعتبرت الدراسـة أن التوجـه المستقبلى عامل يحمى من السـوكيات المنحرفة والعدوانية.

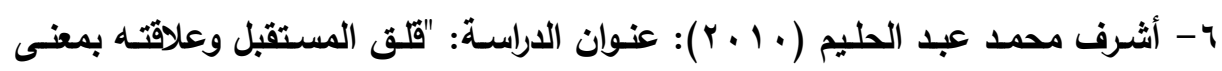
الحياة والضـغوط النفسية للى عينـة من الشباب". هدف الدراسـة: هدفت الدراسة إلى لى

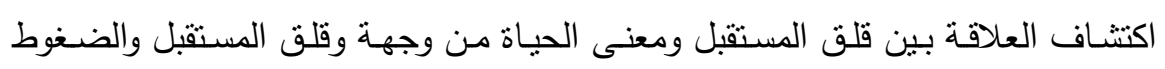

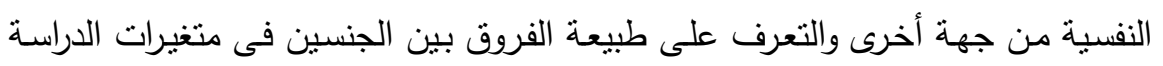

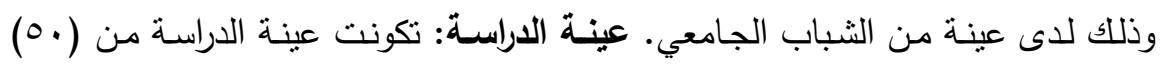

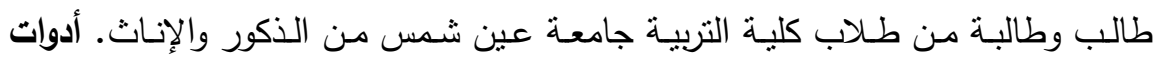

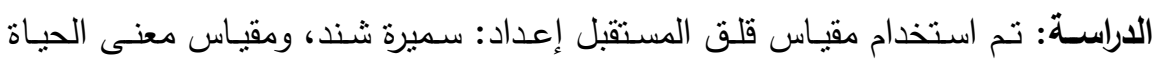
إعداد: نجوى إبراهيم، ومقياس الضغوط النفسية إعداد: نجـلاء عبد المعبود على أفراد إداد

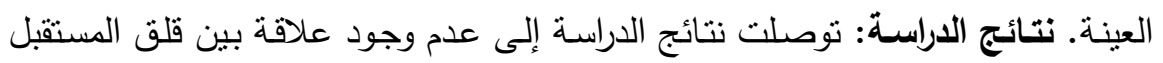

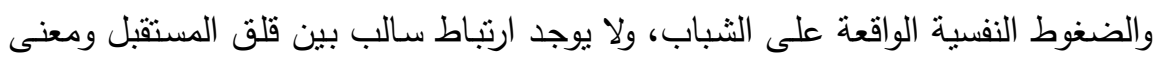
الحياة، وعدم وجود فروق بين الذكور والإناث فى الثعور بقلق المستقبل.

تعقيب عام على الدراسات السابقة: أولاً : التعقيب الخاص بالدراسـات السـابقة المتعلقة بمتغير إضطراب كرب مـا بعد الصدمه:

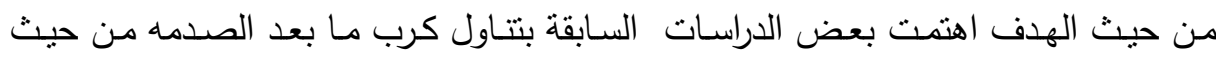

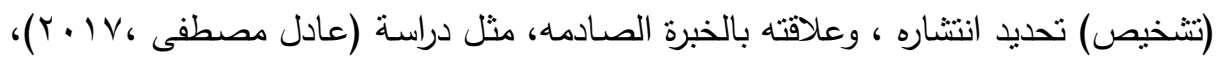

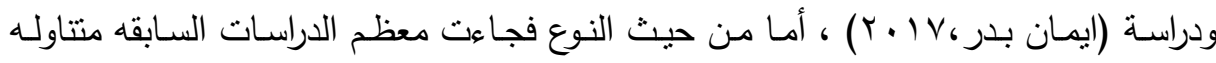

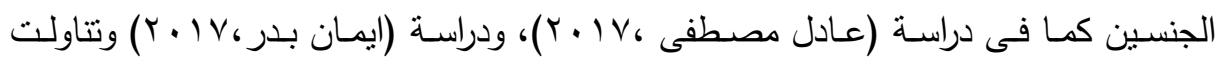

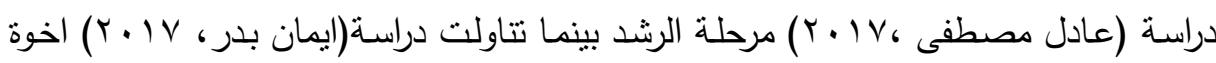

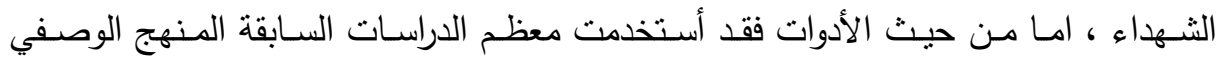
التحليلي، كما استخدمت بعض الدراسـات قائمـة فحص أعراض إضطرابات الضـغوط التاليه 238

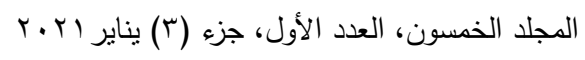

$$
\begin{aligned}
& \text { الترقيم الدولي 0826- ISSN 1110 }
\end{aligned}
$$




\section{مجلة العلوم البيئية

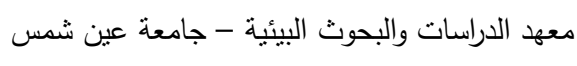 مروة شحاتة ابراهيم عبد الحكيم وآخرون}

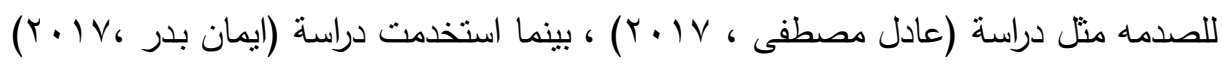

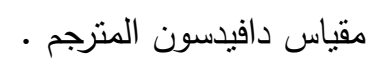
ثانياً:التعقيب الخـاص بالدراسـات السـابقة المتعلقة بمتغير مفهوم الذات: من حيث الهدف

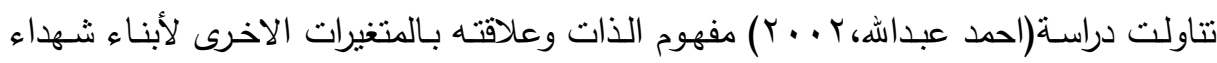

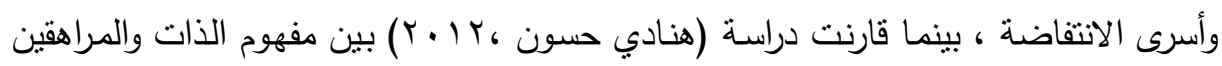

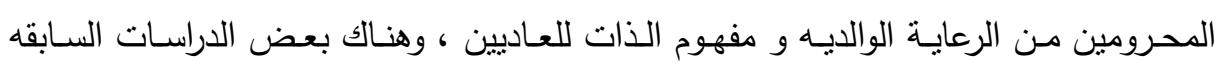

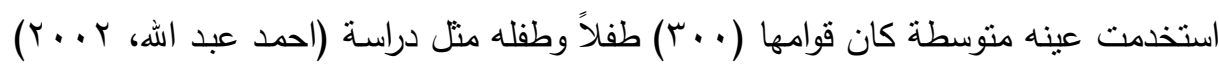

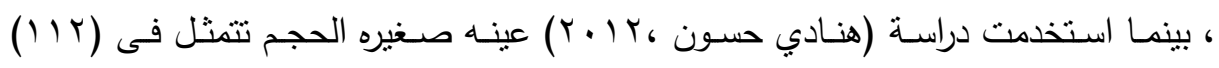

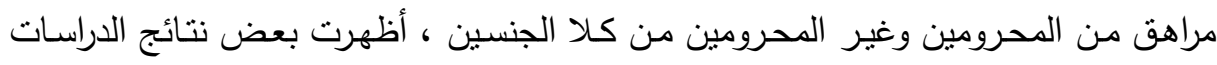
السابقة ان ابناء الثهداء الأناث تثقوقن على الذكور في مفهوم الذات مثل دراسة (احمد عبداله

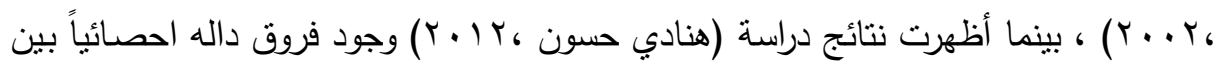

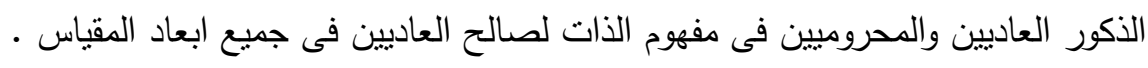

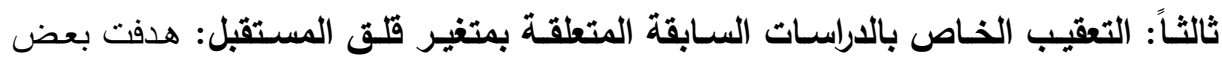

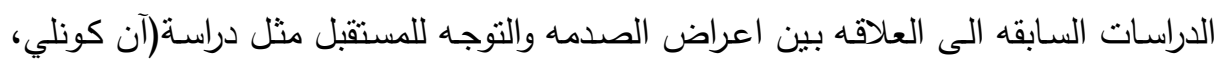

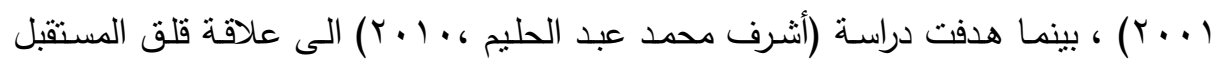

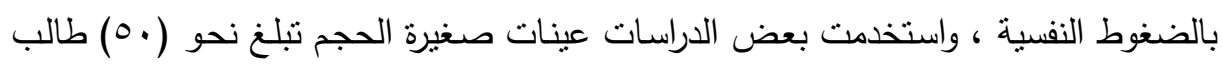

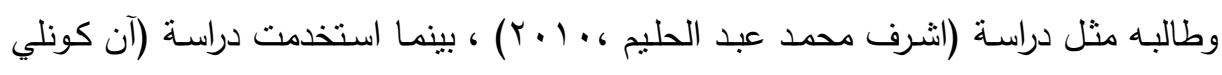

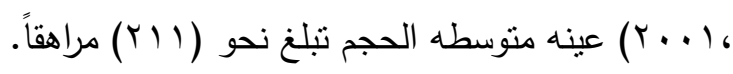

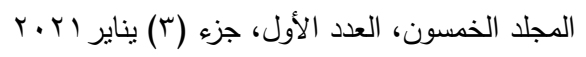

$$
\begin{aligned}
& \text { الترقيم الدولي 0826- ISSN 1110 }
\end{aligned}
$$




\section{هروض المهمه}

تحددت فروض الدراسة الحالية فيما يلي: فى ضوء ما ثم عرضها فى الإطار النظري وبناءاً

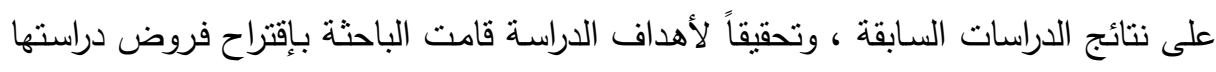

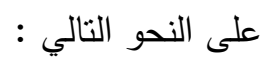

الفـرض الأول : توجد علاقـة ارتباطيـة دالـة احصـائياً بـين كرب مـا بعد الصـدمة ومفهوم الذات.

الفـرض الثناني: توجـد علاقـة ارتباطيـة دالـة احصـائياً بـين كـرب مـا بعـد الصـدمة وقلـق المستقبل.

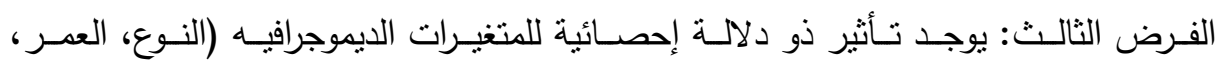

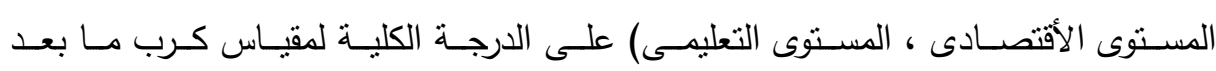

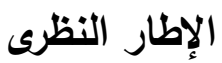

أولاً: كرب ما بعد الصدمة: ظهر هذا النوع من الإضطراب على هيئة رد فعل طويل

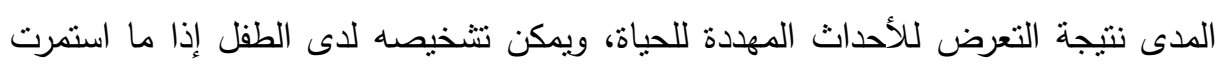

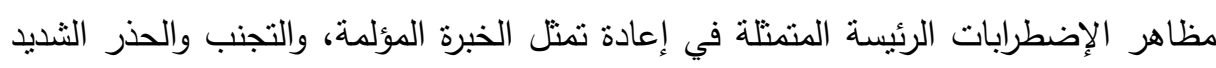

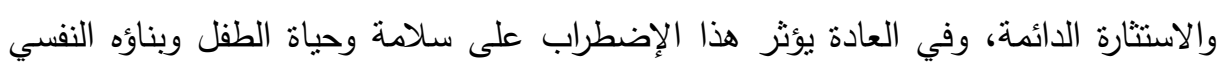

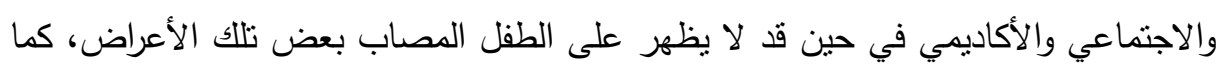

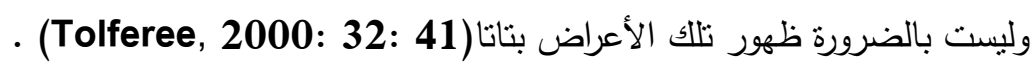
العوامل التى يتوقف عليها تثخيص إضطراب كرب مابعد الصدمة (ماهر عمرو: V. . . ب) :

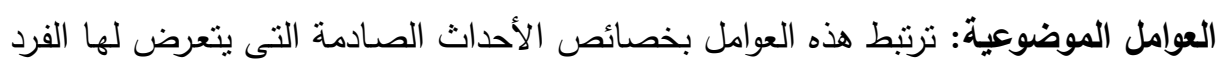

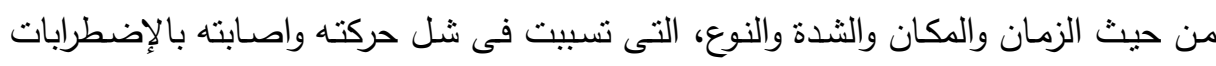
الانفعاليه.

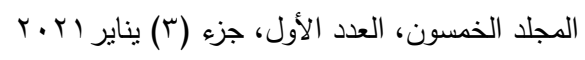

$$
\begin{aligned}
& \text { التزقيم الدولي 0826- ISSN 1110 بناير الإن }
\end{aligned}
$$


العوامسل الذاتيـة الثخصـية: ترتبط هذه العوامل بسمات وخصـائص الفرد وتقاليده وعاداتـه واتجاهاته وقيمه وكل مايتعلق بذاته ثانياً: مفهوم الأات: يعد مفهوم الذات الجانب الأساسي الذى يحدد للمراهق شخصيته، ولعل الانسان هو المخلوق الوحيد الذى يستطيع ان يدرك ذاته، ويجعل منها موضوعاً للنأمل

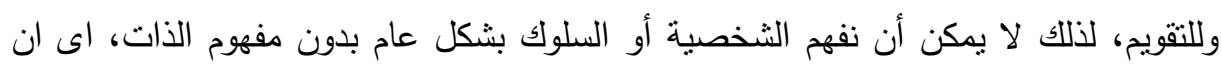

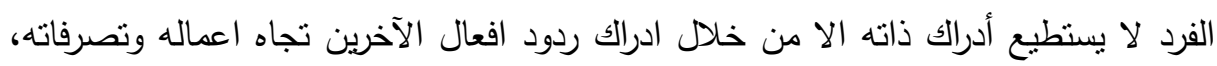

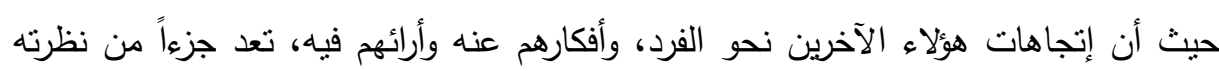

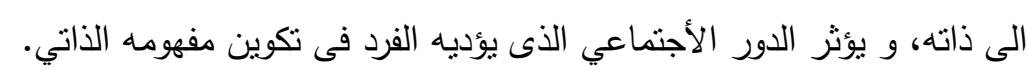

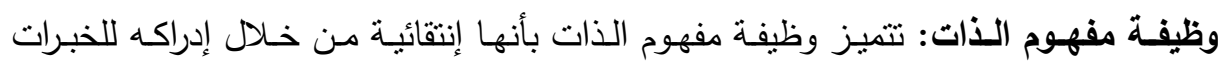

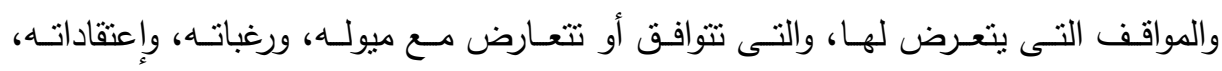

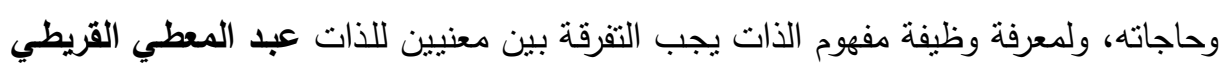

ثالثثاً: قلق المستقبل: لم يشهد عصر من العصور منل ما يشهده عصرنا الحالى من التوترات والازمات والضغوط النفسيه بالإضافه الى التغيرات السريعه والتطورات الكبيره وما

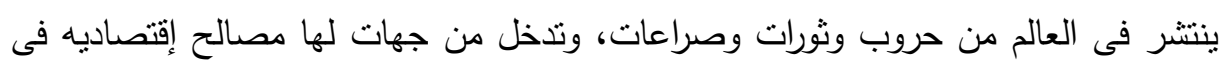

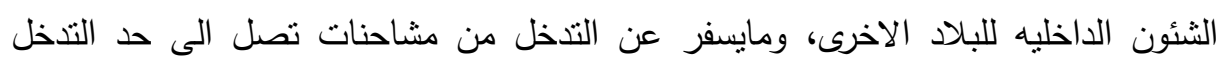
العسكري ولاسيما الثرق الاوسط من هذا التذخل مثال العراق وليبيا وسوريا والارض الاضن المنتلة "فلسطين" ومايعانى شعوب هذه البلاد المنكوبه من اضرار نفسية واجتماعية واقتصاديه وزيادة

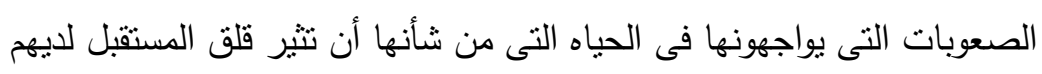

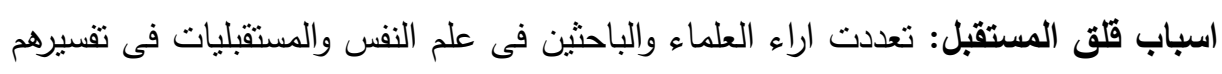

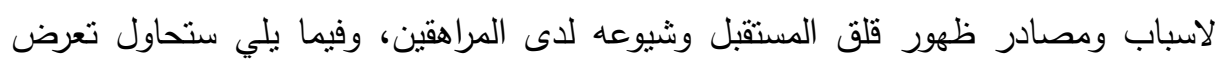

$$
\text { الباحثة أهم هذه الاسباب: }
$$

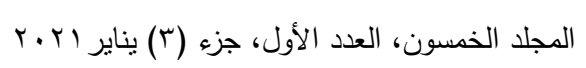

$$
\begin{aligned}
& \text { الترقيم الدولي 0826-1110 1SSN }
\end{aligned}
$$




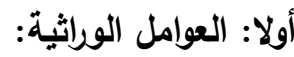

الاستعداد الوراثى فى بعض الحالات، وتختلط العوامل الوراثية بالعوامل البيئية.

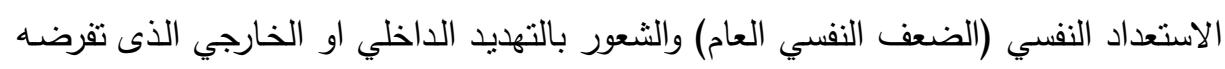

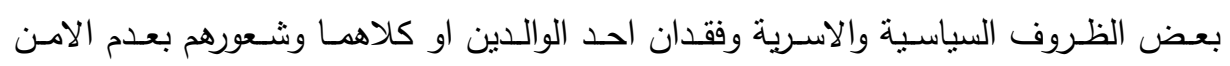
والامان.

ثانيا: التنشئة الاجتماعية والأسرية " الاسرة وتأثير الوالدين ":

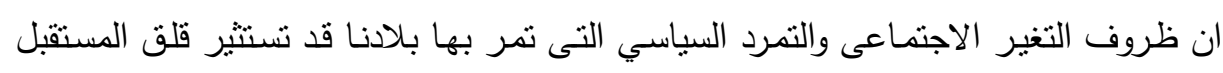

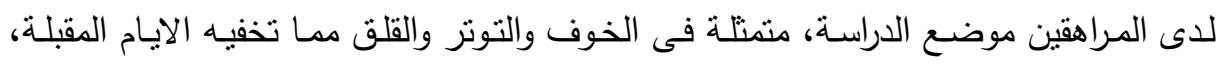
الامر الذى يدعو المراهقين الى اعادة النظر فى خططهم واهدافهم بما يتتاسب مـع التغيير الاجتماعى والسياسي والاسري ولاسيما من فقدان احد الوالدين او كليهما (فى ثورة اعثى مب يناير ) فهم عرضة للخوف المستقبلي سوء من الناحية المادية، الاجتماعية، السياسية، وييقى التغيير

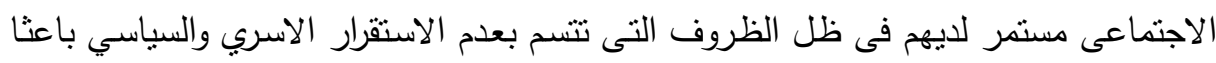

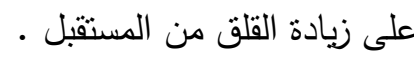
رابعا: المراهقة: تعد فترة المراهقة من أهم الفترات التى يمر بها الإنسان فى حياته الطبيعية،

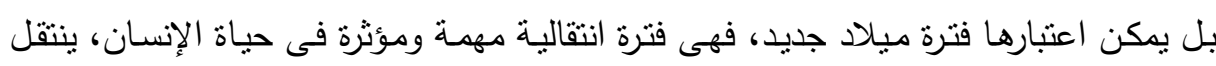
فيها الفرد من مرحلة الطفولة نحو الرجولة، وقد اختلف الباحثون فى تحديد بدايتها ونهايتها بشكل دقيق، ويرجع ذلك إلى تتوع طبائع الشعوب، وتعدد ثقافاتها، وإختلاف الفترات الزمانية،

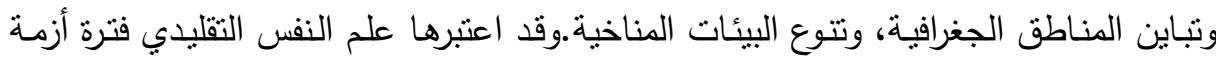

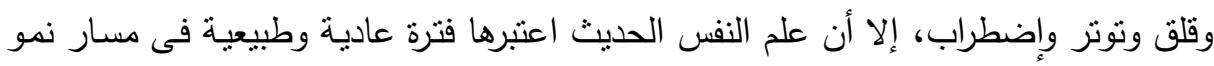

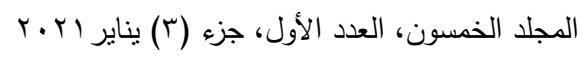

$$
\begin{aligned}
& \text { الترقيم الدولي 0826-0SN 1110 }
\end{aligned}
$$


خامساً: الثورة: هو التغيير الذى يحثثه الثعب من خلال أدواته كالقوات المسلحة، أو من

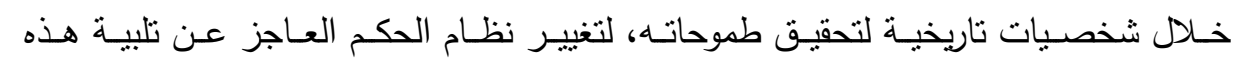
الطموحات.

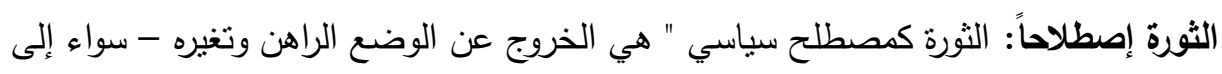

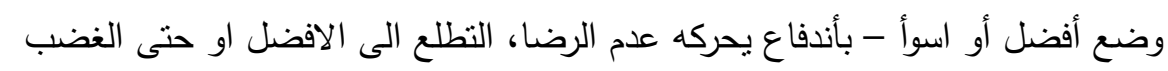

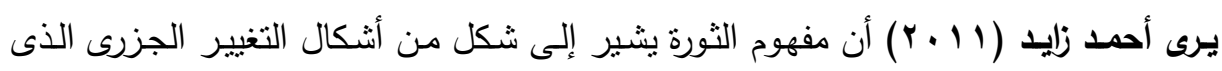

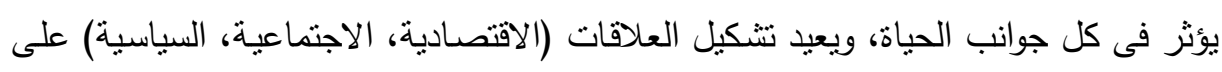
أسس جديدة وييداء هذا التغيير الجزري بتغيير شكل الأبنية النظامية للقوة، أى تغيير النظام السياسي فى وقت قصير نسبيا.

\section{إجراء|ت البحث}

أ- منهج البحث: نم الاعتماد فى هذا البحث على المنهج الوصفى حيث أنهأحد أنثكال التحليل والتفسير العلمى. ب- بدود البحث :

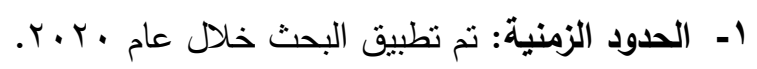

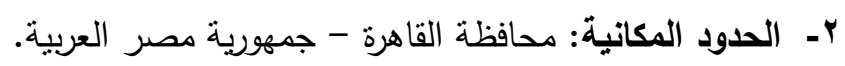

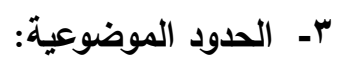

أ- الأدوات المستخدمة: مقياس اضراب كرب ما بعد الصدمة الصدة من برنامج غزة للصحة

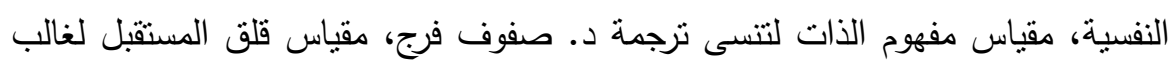

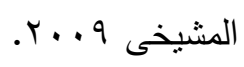

ب- مجتمع وعينة الدراسة: يتألف المجتمع الأصلى من جميع أبناء الثهداء فى القاهرة،

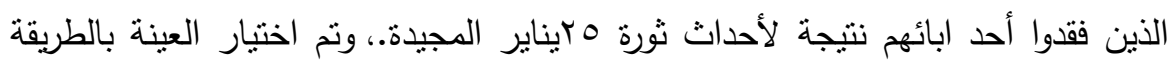

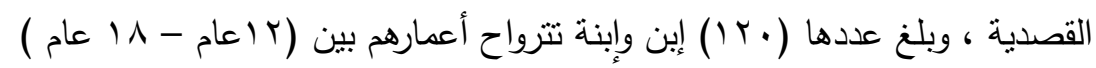

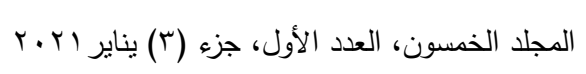

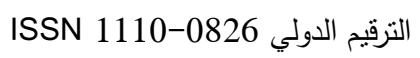


مجلة العلوم البيئية

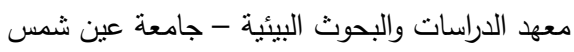

مروة شحاتة ابراهيم عبد الحكيم وآخرون

جلول (1): يوضح توزيع العينة حسب متغيرات الديموجرافية

\begin{tabular}{|c|c|c|c|c|c|c|c|c|c|c|c|}
\hline$\%$ & s & العمر & $\%$ & ك & الاقتصادي & $\%$ & s & التعليمي & $\%$ & ك & النوع \\
\hline $17, \mathrm{~V}$ & $r$. & من كا عا عام - & $17, V$ & $r$. & منخفض & $r \cdot, \wedge$ & ro & ملتحق & 0 . & 7. & ذكور \\
\hline $\mid \wedge, r$ & Kr & 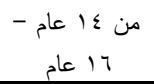 & $V 4, v$ & Qr & متوسط & $r v, 0$ & <0 & تكومي & 0 . & 7. & إناث \\
\hline $10,$. & $\mathrm{VA}$ & من 17 العام- & $7, \mathrm{~V}$ & $\wedge$ & مرتفع & $\varepsilon 1, v$ & 0. & خاص & & & \\
\hline $1 \ldots$ & $i r$. & الإجمالى & $1 \ldots$ & Ir. & الإجمالى & $1 \ldots$ & $i r$. & الإجمالي & $1 \ldots$ & $i r$. & الإجمالي \\
\hline
\end{tabular}

أولاً: مقياس إضطراب كرب ما بعد الصدمة من إعداد برنامج غزة للصحه النفسيه:

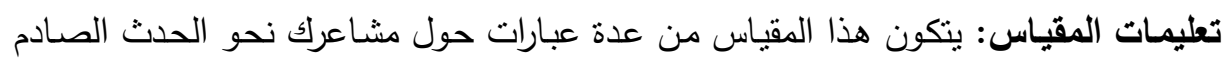
الذى تعرضت له، وقد أعطى لكل عبارة ثلاثة إختيارات، عليك أن تقرأ كل عبارة بدقة وتحدد

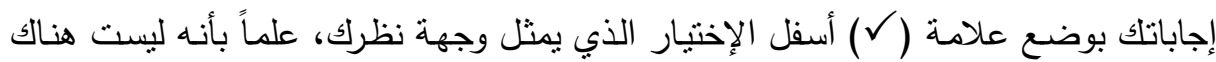

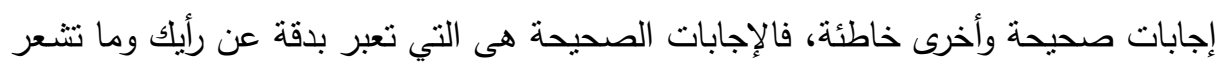
به بالفعل. وصف المقيساس : يتكون المقياس من (9 (1) فقرة، إذ قامت الباحثة بتحديد بدائل المقياس

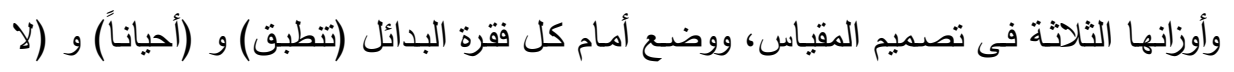
تتطبق) مع أوزانها وعلى وفق إتجاهها، إذا كانت القوة إيجابية يكون التصحيح (T، Y، I ).

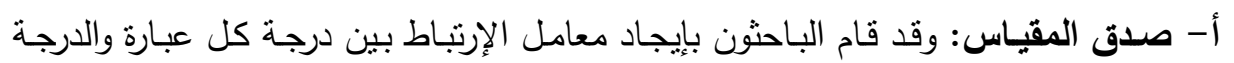

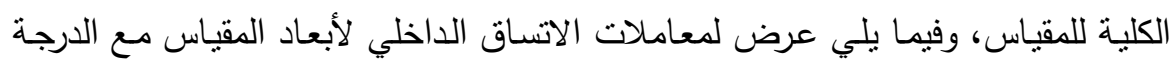
الكلية كالآتي: - n

$$
\begin{aligned}
& \text { المجلد الخمسون، العدد الأول، جزء (r) يناير اب.r. } \\
& \text { الترقيم الدولي 0826-0SN 1110 }
\end{aligned}
$$


مجلة العلوم البيئية

معهد الدراسات والبحوث البيئية - جامعة عين شمس له مروة شحاتة ابراهيم عبد الحكيم وآخرون جـان

جدول (Y): يوضح صدق الاتساق الداخلي لعبارات مقياس الكرب

\begin{tabular}{|c|c|c|c|}
\hline معامل الارتباط & رقم العبارة & معامل الارتباط & رقم العبارة \\
\hline "*.,$\leq Y_{0}$ & 11 & $", r q r$ & 1 \\
\hline "., & IT & "**." $\cdot \leq \Psi)$ & $r$ \\
\hline$" *, \varepsilon \cdot \wedge$ & $1 \pi$ & $* *, \leqslant Y 0$ & r \\
\hline$\cdot, r \wedge \wedge$ & $1 \leq$ & $* *, \leq \leqslant \Gamma$ & $\varepsilon$ \\
\hline$" *, \leq \leqslant 7$ & 10 & $" *, \varepsilon \cdot r$ & 0 \\
\hline ".,rqr & 17 & $"$ ", YAT & 7 \\
\hline " וח & iv & ".,LIV & V \\
\hline " & 11 & ". & $\Lambda$ \\
\hline$" \cdot, Y \wedge \vee$ & 19 & ".., $0 . r$ & 9 \\
\hline & & $" *, \varepsilon r \leq$ & 1. \\
\hline
\end{tabular}

يتضح من الجدول السابق أن جميع قيم معاملات الارتباط دالة إحصائيًا عند مستوى

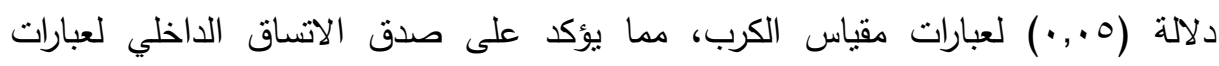
المقياس.

ب- ثبات المقيـاس: للتحقق من ثبات المقياس استخدم الباحثون معادلة ألفا (Alpha)، ويوضح الجدول التالي معاملات الثبات الناتجة باستخدام هذه المعادلة.

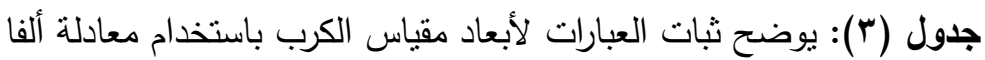

\begin{tabular}{|c|c|c|}
\hline قيمة ألفا & عدد العبارات & أبعاد المقياس \\
\hline., $7 \pi q$ & 19 & الارجة الكلية لمقياس الكرب \\
\hline
\end{tabular}

يتضح من الجدول السابق أن قيم معاملات الثبات لأبعاد مقياس الكرب قيم مرتفعة حيث

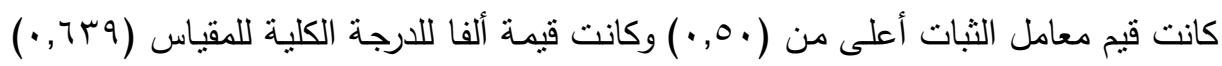
وهي قيمة مرتفعة.

التزقيم الدولي 0826-1110 1SSN 


\section{ثانياً: مقياس مفهوم الأت لتنسي:}

تعليمات المقياس :عزيزي المفحوص، العبارات التالية تساعدك على وصف نفسك كما تراها، أجب عن هذه العبارات كما لو كنت تصف نفسك لنفسك، أقرأ كل على عبارة بعنايـة ثم إختر

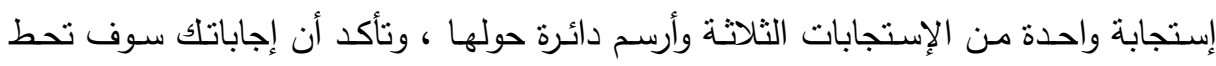

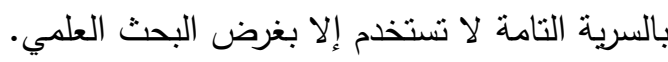
وصف المقياس: يتكون المقياس من (r) فقرة مقسمة إلى خمسة أبعاد، إذ قامت الباحثنة

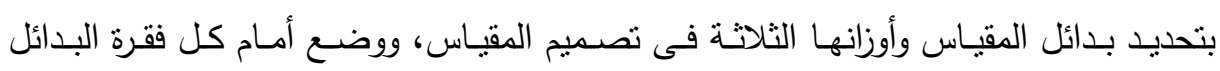
(تنطبق) و (أحباناً) و (لا تتطبق) مع أوزانها وعلى وفق إتجاهها، إذا كانت القوة إيجابية يكون

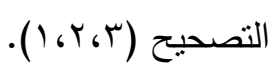

\begin{tabular}{|c|c|c|}
\hline عدد العبارات & آرقام العبارات & البعد \\
\hline 11 & 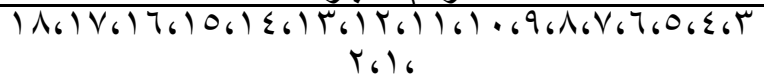 & الألماجلاقية \\
\hline $1 \mathrm{i}$ & 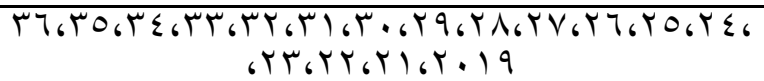 & مفهوم الذات الثخبة \\
\hline 11 & 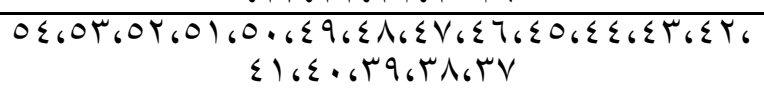 & مفهوم الأذاتة \\
\hline 11 & $\begin{array}{c}V Y_{6} V 16 V \cdot 67967167 V_{6} 7767067567 T 677 Y_{6} 7167 \cdot, \\
09,0 \Lambda_{6} 0 V_{6} 07600\end{array}$ & الاجنماعية \\
\hline 1. & $\left.\Lambda r_{6} \wedge\right)_{6} \Lambda_{6}{ }_{6} V 9_{6} V \Lambda_{6} V V_{6} V T_{6} V 0_{6} V \varepsilon_{6} V r$ & مفهوم نقات \\
\hline AT & الارجة الكلية & \\
\hline
\end{tabular}

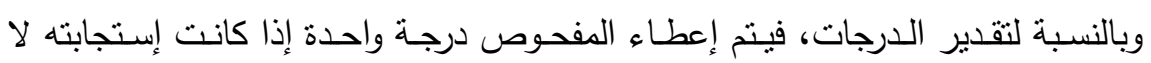
تتطبق، ودرجتان إذا كانت إستجابته أحياناً، وثلاثة درجات إذا كانت إستجابته نتطبق، بحيث

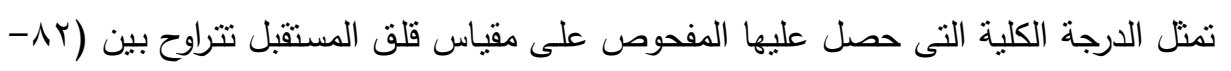

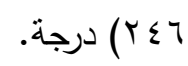

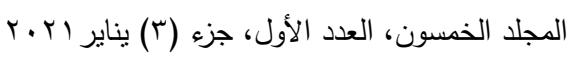

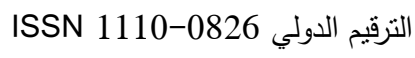


الخصائص السيكوميترية الأصلية للمقياس:

أ- صدق المقياس: وقد قام الباحثون بإيجاد معامل الإرتباط بين الدرجة الكلية للبعد والدرجة لإنيانة

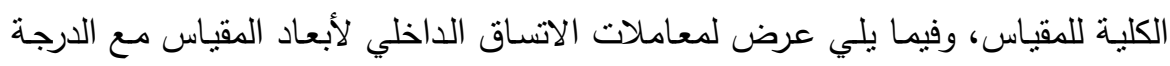
الكلية كالآتي:

جدول (•): يوضح صدق الاتساق الداخلي لأبعاد مقياس مفهوم الذات مع الدرجة الكلية للمقياس

\begin{tabular}{|c|c|c|}
\hline \multicolumn{2}{|c|}{ الارجةٌ الكلية لمقياس الأمن النفسى . } & \multirow{2}{*}{ المتفيرات } \\
\hline الالالةُ المعنويةٌة & معامل ارتباط بيرسون & \\
\hline$\cdot, \cdots 1$ & $\cdot$, Атr & البعد الاول: مفهوم الذات الاخلاقية \\
\hline$\cdot, \cdots 1$ & $\cdot, \vee \vee \vee q$ & البعد الثانى: مفهوم الذات الشخصية \\
\hline$\cdot, \cdots 1$ & $\cdot, 91 \mathrm{~V}$ & البعد الثَالث: مفهوم الأتات الأسريةة \\
\hline$\cdot, \cdots 1$ & $\cdot, 9 \ldots$ & البعد اليرابع: مفهوم الذات الاجتماعيةٍ \\
\hline$\cdot, \ldots 1$ & $\cdot$, , АTा & البعد الخامس: مفهوم نقا الذات \\
\hline
\end{tabular}

يوضح الجدول السابق صدق الاتساق الداخلي لمقياس مفهوم الذات وجد أن قيم معامل

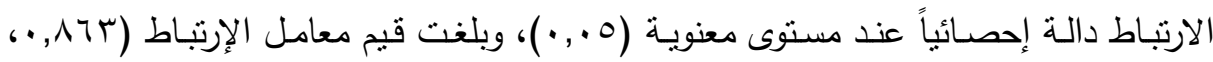

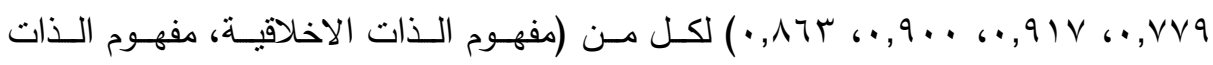

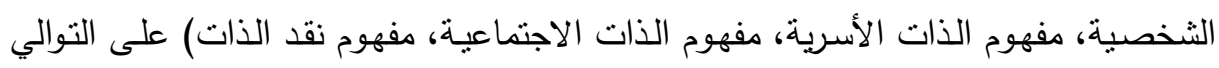
وهي قيم تؤكد على صدق المقياس. ب- ثبات المقيـاس: للتحقق من ثبات المقياس استخدم الباحثون معادلـة ألفا (Alpha)، ويوضح الجدول التالي معاملات الثبات الناتجة باستخدام هذه المعادلة. 
مجلة العلوم البيئية

معهز الدراسات والبحوث البيئية - جامعة عين شمس لهن مروة شحاتة ابراهيم عبد الحكيم وآخرون

جلول (†): يوضح ثبات العبارات لمقياس مفهوم الذات باستخدام معادلة ألفا

\begin{tabular}{|c|c|c|}
\hline قيمة آلفا & عدد العبارات & أبعاد المقياس \\
\hline$\cdot, 9 \wedge \mathrm{V}$ & 11 & البعد الاول: مفهوم الأات الاخلاقِيةة \\
\hline$\cdot, 991$ & 11 & البعد الثانى: مفهوم الأات الثخصية \\
\hline$\cdot, \lambda) \leqslant$ & 11 & البعد الثالث: مفهوم الذات الأسرية \\
\hline$\cdot, 9 \vee V$ & 11 & البعد الرابع: مفهوم الذات الاجتماعية \\
\hline$\cdot, 940$ & 1 . & البعد الخامس: مفهوم نقد الذات \\
\hline$\cdot, 901$ & NY & الارجة الكلية لمقياس مفهوم الأات \\
\hline
\end{tabular}

يتضح من الجدول السابق أن قيم معاملات الثبات لأبعاد مقياس مفهوم الذات قيم مرتفعة

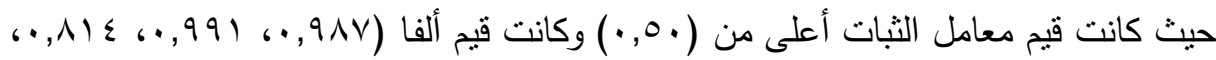

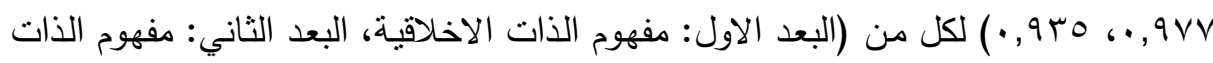

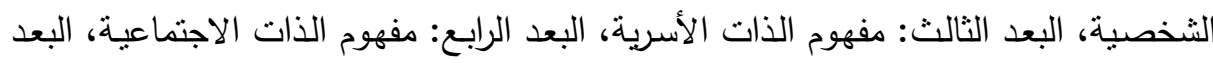

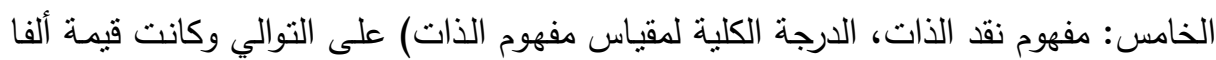
للارجة الكلية للمقياس (901, · • ) وهي قيمة مرتفعة.

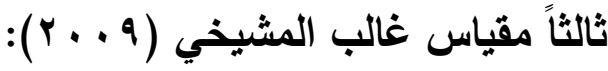
تعليمات المقياس: توجد مجموعة من العبارات على المفحوص أن يقرأ كل عبارة بدقة ويحدد

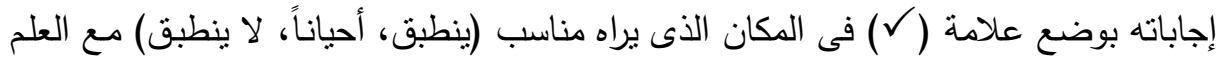
أنه لاتوجد إجابات صحيحة وأخرى خاطئة وإنما الإجابة المناسبة هى ما تتطبق علئ عليك فعلاً. وصف المقياس: يتكون المقياس من (Tء) فقرة مقسمة إلى خمسة أبعاد، إذ قامت الباحثة

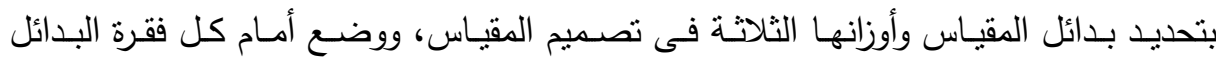
(تنطبق) و (أحياناً) و (لا تنطبق) مع أوزانها وعلى وفق إتجاهها، إذا كانت القوة إيجابية يكون

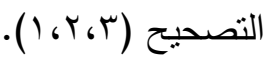




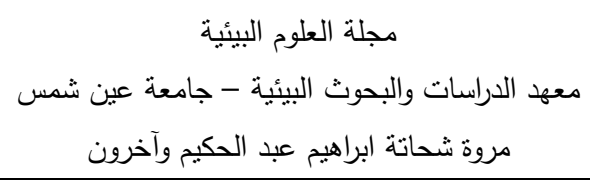

\begin{tabular}{|c|c|c|}
\hline عدد العبارات & آرقام العبارات & البعد \\
\hline$\wedge$ & 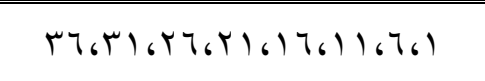 & التفكير الستبلبي تجاه \\
\hline 9 & $\left.\left.\sum I_{6}, Y_{6} Y_{6} Y_{1} V_{6} Y_{6}\right) V_{6}\right) Y_{6} V_{6} Y$ & النظرة السلبية للحياة. \\
\hline 9 & $\left.\left.\varepsilon r_{6} \mu_{6} \mu \mu_{6} r \Lambda_{6} r r_{6}\right) \Lambda_{6}\right) r_{6} \Lambda_{6} r$ & القلق من الأحداثة الحياتية \\
\hline$\Lambda$ & $\left.r q_{6} r \leq 6 r q_{6} r \leq 619_{6}\right) \leq 6 q_{6} \varepsilon$ & المظاهر النفسية: لقلق \\
\hline 9 & 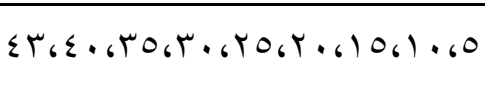 & المظاهر الجسبمية لقلق \\
\hline$\varepsilon \mu$ & جة الكلية & \\
\hline
\end{tabular}

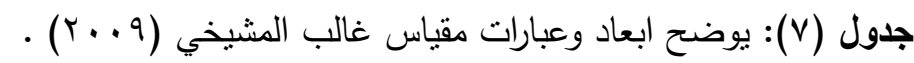

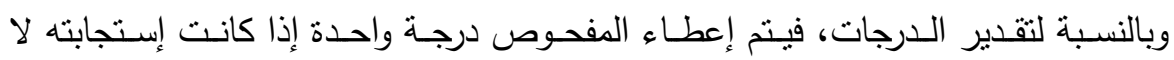
تتطبق، ودرجتان إذا كانت إستجابته أحياناً، وثناثة درجات إذاء كانت إستجابته تتطبق، بحيث

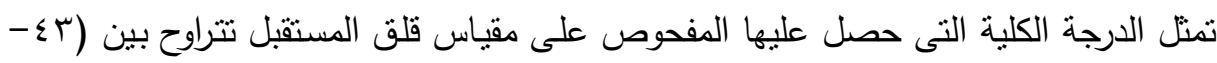

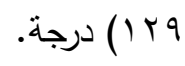
الخصائص السيكوميترية الأصلية للمقياس: أ- صدق المقياس: وقد قام الباحثون بإيجاد معامل الإرتباط بين الدرجة الكلية للبعد والدرجة الدئة

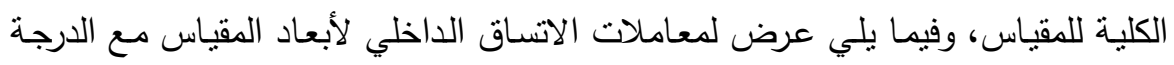

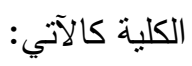

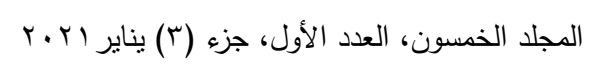

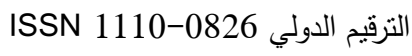


جدول (^): يوضح صدق الاتساق الداخلي لأبعاد مقياس قلق المستقبل مع الدرجة الكلية للمقياس

\begin{tabular}{|c|c|c|}
\hline \multicolumn{2}{|c|}{ الارجةٌ الكلية لمقياس قلثق المستقبل } & \multirow[b]{2}{*}{ المتغيرات } \\
\hline المعنوية & معامل ارتباط & \\
\hline$\cdot, \cdot \varepsilon$ & •, & البعد الاول: التفكير السلبي تجاه المستقبل \\
\hline$\cdot, \ldots 1$ & $\cdot, 791$ & البعد الثانحي: النظرة السلبية للحياة \\
\hline$\cdot, \cdots 1$ & $\cdot, \mathrm{V}$ 个人 & الضاغطدة الثالث: القلق من الاحداث الحياتية \\
\hline$\cdot, \ldots 1$ & $\cdot, \wedge \leq 0$ & البعد الرابع: المظاهر النفسية لقلق المستقبل \\
\hline$\cdot, \ldots 1$ & $\cdot, \Lambda \leqslant \mu$ & البعد الخامس: المظاهر الجسمية لقّق المستقبل \\
\hline
\end{tabular}

يوضح الجدول السابق صدق الاتساق الداخلي لمقياس قلق المستقبل وجد أن قيم معامل

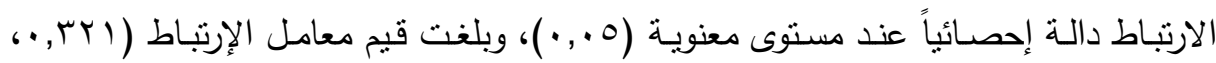

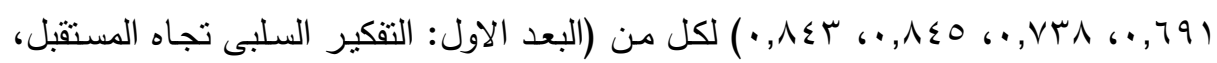

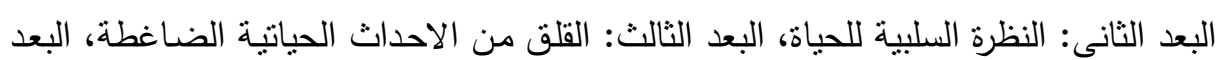

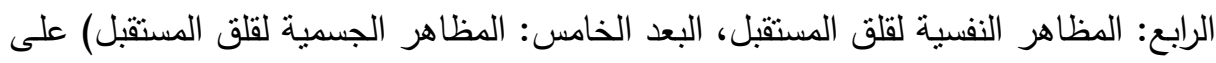

$$
\text { التوالي وهي قيم تؤكد على صدق المقياس. }
$$

ب- ثبـات المقبـاس: للتحقق مـن ثبـات المقيـاس اسـتخدم البـاحثون معادلـة ألفـا (Alpha)، ويوضح الجدول التالي معاملات الثبات الناتجة باستخدام هذه المعادلة.

جدول (9): يوضح ثبات العبارات لأبعاد مقياس فلق المستقبل باستخدام معادلة ألفا

\begin{tabular}{|c|c|c|}
\hline قِيمة آلفَا & عدد العبارات & آبعاد المقياس \\
\hline., 091 & 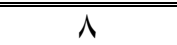 & السلبي تجاه المستقبل \\
\hline$\cdot, \times 97$ & $\bar{q}$ & البعد الثاني،: النظرة السلبية للحباة \\
\hline$\cdot, 9 \vee \wedge$ & 9 & البعد الثالث: القلق من الاحداث الحباتبة الضاغطة \\
\hline$\cdot, 9 \wedge 7$ & $\Lambda$ & البعد الرابع: المظاهر النفسية لقلق المستقبل \\
\hline$\cdot, 99$ & 9 & البعد الخامس: المظاهر الجسمية لقلق المستقبل \\
\hline$\cdot, 97 \mathrm{~V}$ & $\varepsilon \pi$ & الارجة الكلية لمقياس قلق المستقبل \\
\hline
\end{tabular}

$$
\begin{aligned}
& \text { المجلد الخمسون، العدد الأول، جزء (r) يناير اب.r. } \\
& \text { الترقيم الدولي 0826-0SN 1110 }
\end{aligned}
$$


يتضح من الجدول السابق أن قيم معاملات الثبات لأبعاد مقياس قلق المستقبل قيم

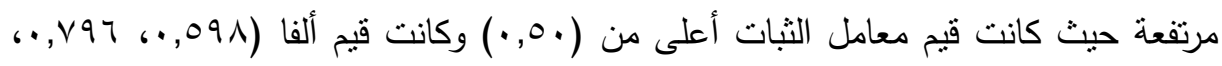

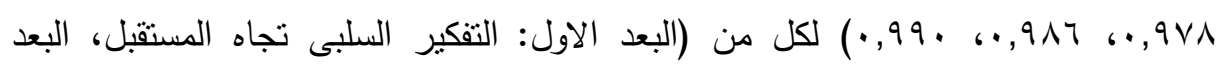

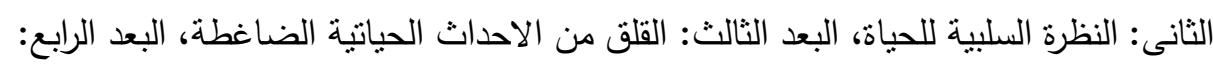
المظاهر النفسية لقلق المستقبل، البعد الخامس: المظاهر الجسمية لقلق المستقبل) وكانت قيمة ألفا للارجة الكلية للمقياس (97V (9 • ) وهي قيمة مرتفعة.

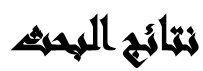

نتائج الفرض الأول وتفسيرها : ينص الفرض الأول على توجد علاقة ارتباطية دالة احصائياً بين كرب ما بعد الصدمة ومفهوم الأت. جدول ( • (1): يوضح العلاقة بين كرب ما بعد الصدمة ومفهوم الذات

\begin{tabular}{|c|c|}
\hline كرب ما بعد الصدمة & المتغبرات \\
\hline معامل الإرتباط & المتيزرا \\
\hline$" *, \Gamma \wedge 1$ & البعد الاول: مفهوم الذات الاخلاقية \\
\hline$\cdot, \sum 94$ & البعد الثاني: مفهوم الذات الشخصية \\
\hline$* *, \leqslant 97$ & البعد الثالث: مفهوم الذات الأسرية \\
\hline$* *, \leqslant \leqslant \wedge$ & البعد الرابع: مفهوم الذات الاجتماعية \\
\hline$" ., 010$ & البعد الخامس: مفهوم نقا الذات \\
\hline${ }^{* *} \cdot, 0 \ldots$ & الارجة الكلية لمقياس مفهوم الذات \\
\hline
\end{tabular}

تبين من الجدول السابق لنتائج العلاقة بين كرب ما بعد الصدمة ومفهوم الذات وجود

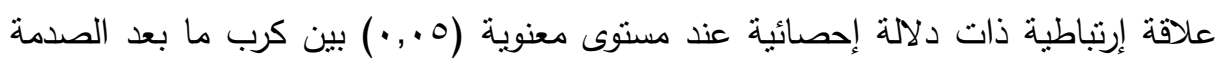

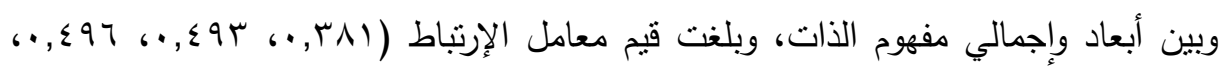
^乏飞, •،

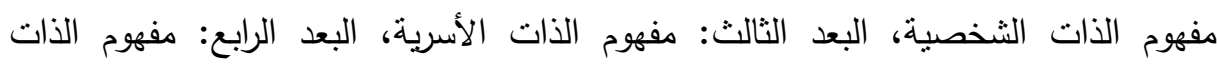

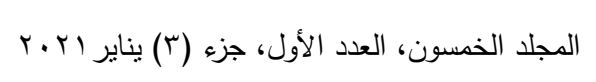


الاجتماعية، البعد الخامس: مفهوم نقد الذات، الدرجة الكلية لمقياس مفهوم الذات) على التوالي. وتقسر الباحثة بأن الأحداث الصادمة التى عاشتها الأسرة منذ نسع أعوام و ترتب عليها

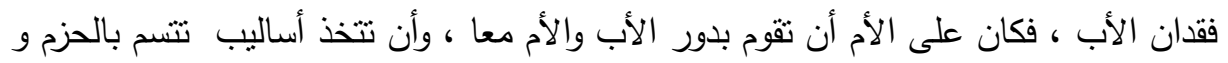

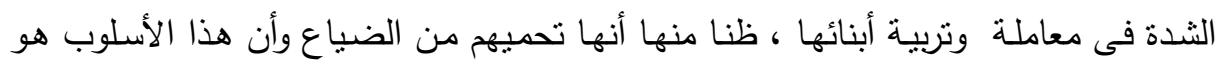

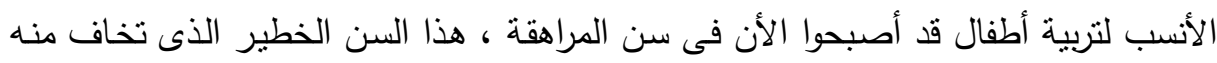

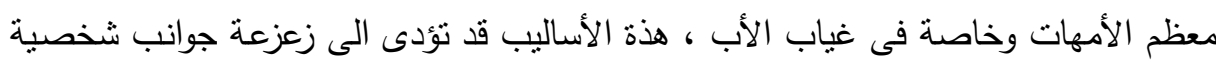

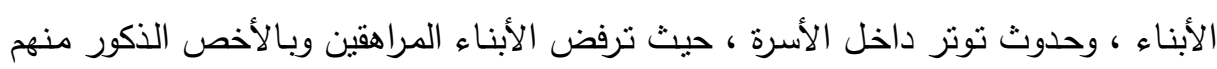

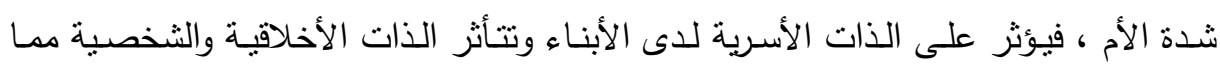

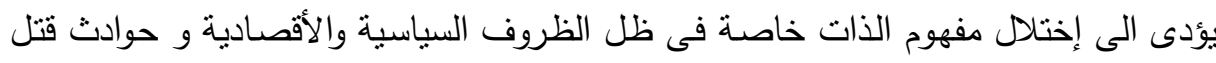

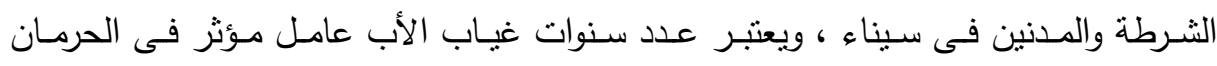

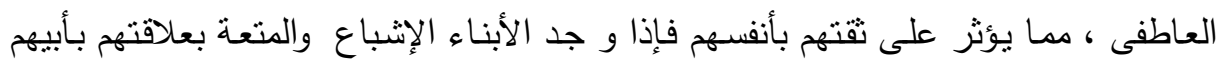
إستطاعوا أن يكونوا علاقات إجتماعية سليمة وصحيحة فى مراحل نموه المختلفة .

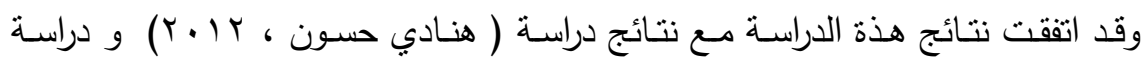

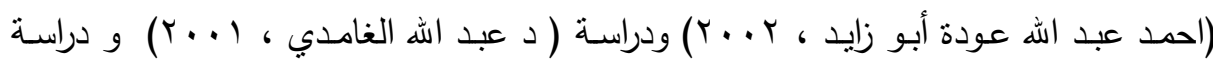

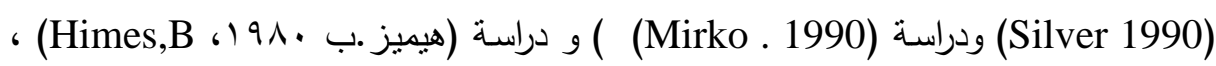

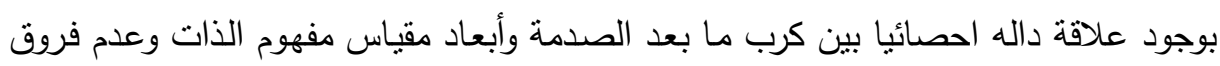

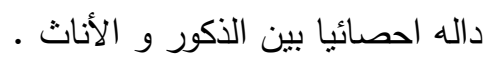

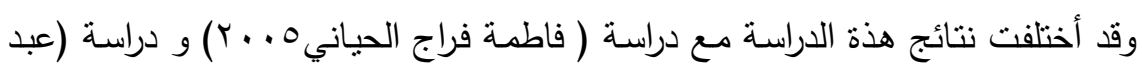

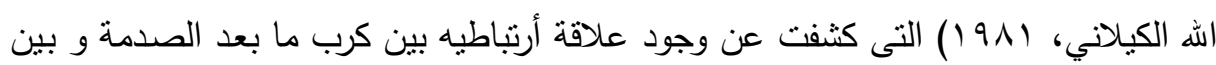

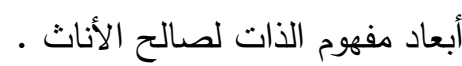
مما سبق ثبت صحة الفرض الأول: توجد علاقة ارتباطية دالة احصائياً بين كرب ما بعد

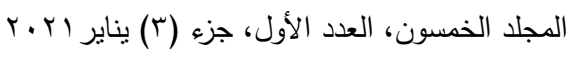

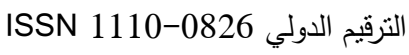


الصدمة ومفهوم الذات.

\section{نتائج الفرض الثانى وتفسيرها :}

ينص الفرض الثانى على :الفرض الثاني: توجد علاقة ارتباطية دالة احصائياً بين كرب ما بعد الصدمة وقظق المستقبل.

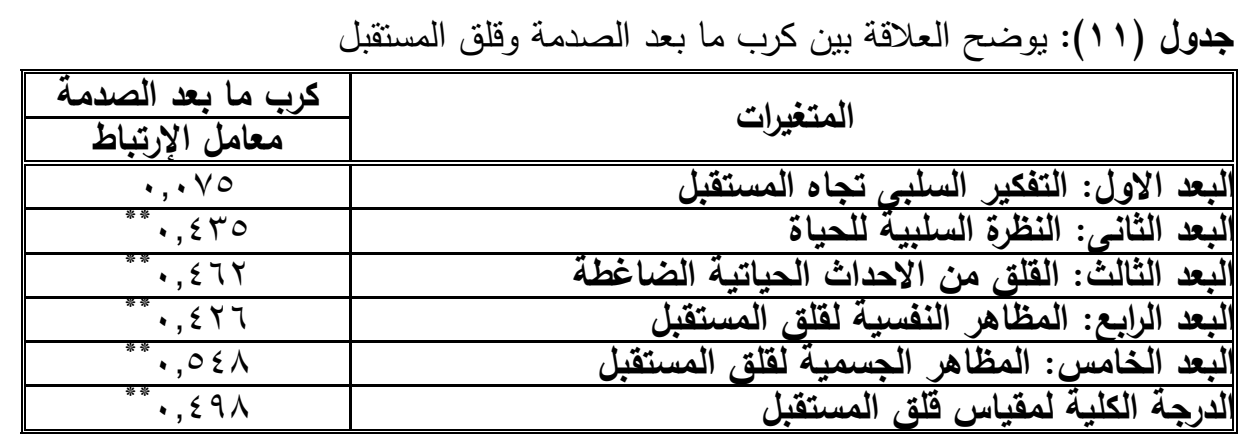

تنين من الجدول السابق لنتائج العلاقة بين كرب ما بعد الصدمة ومفهوم الذات وجود

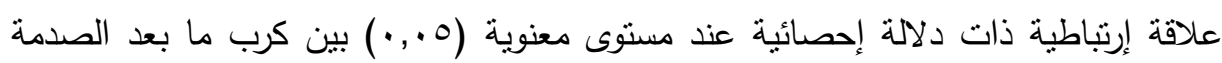

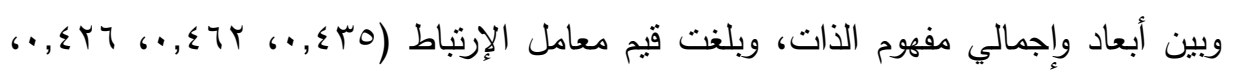

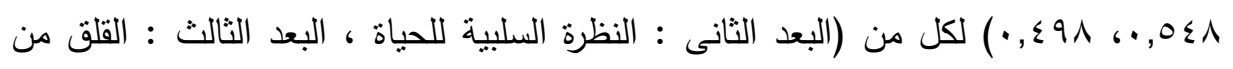

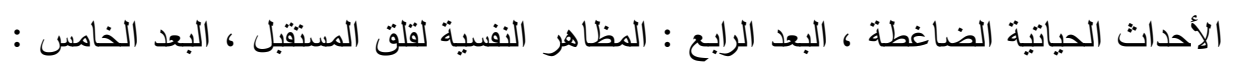

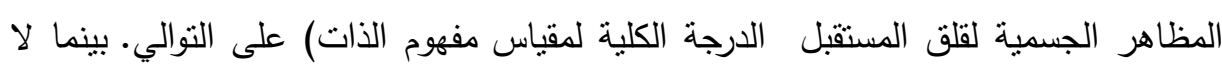

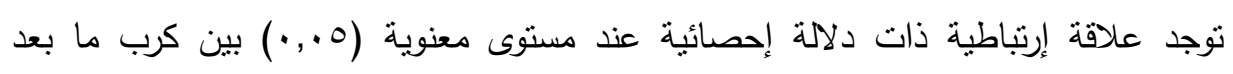
الصدمة وبين البعد الاول: التفكير السلبى تجاه المستقبل.

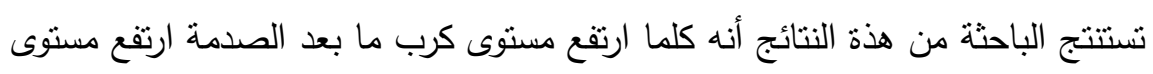

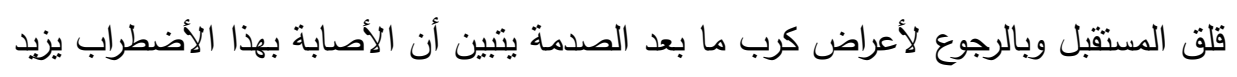

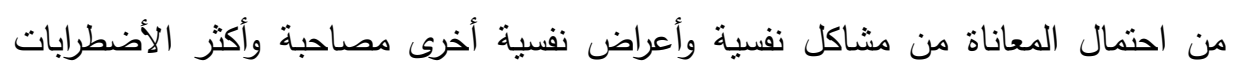

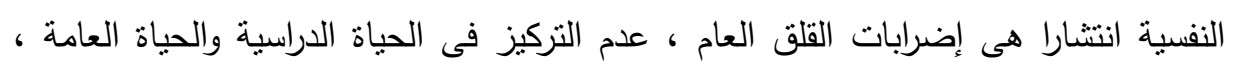

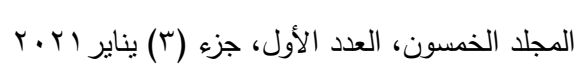

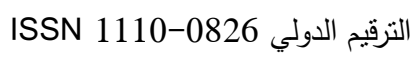




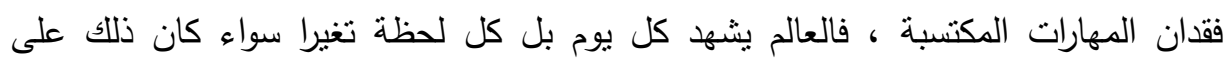

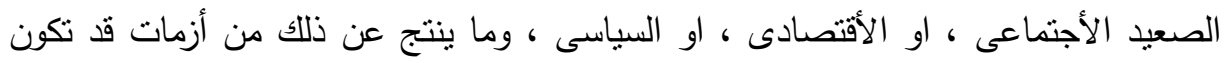

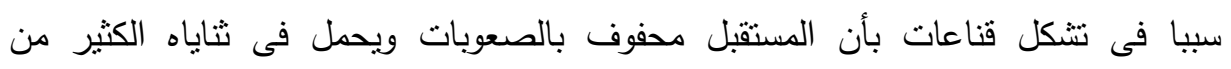
المشكلات ، من هنا كانت العلاقة طردية بين كرب ما بعد الصدمة و قلق المستقبل .

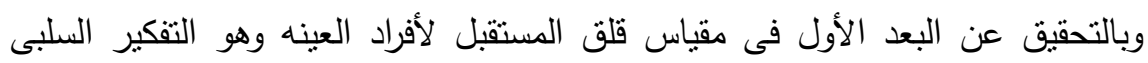

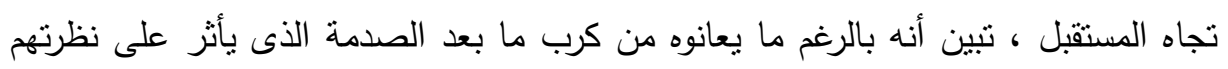

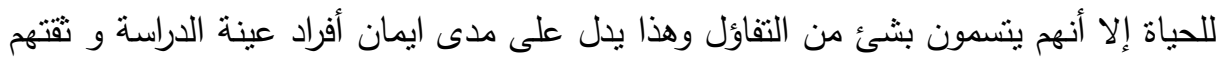

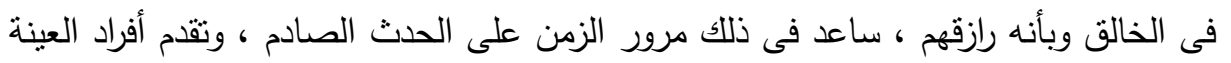

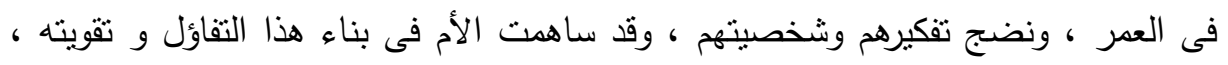

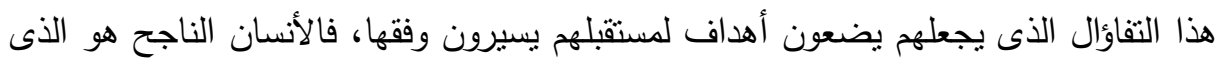
يسير وفق اهداف مرسومة مسبقا ويعمل على تحقيقها ، لذلك لم نجد علاقة ارتباطية ذات

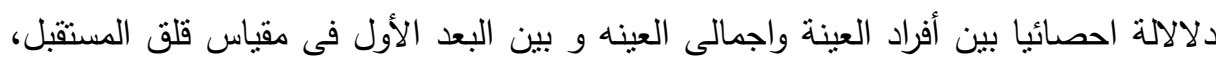

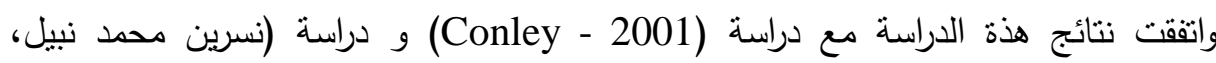

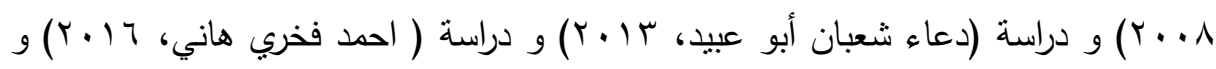

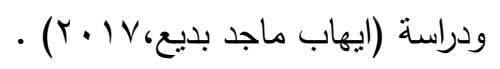

بينما أختلفت نتائج هذة الدراسة مع دراسة (Flynn- 2000) ، و دراسة (باسة ( أثرف محمد

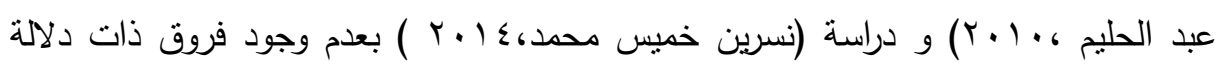

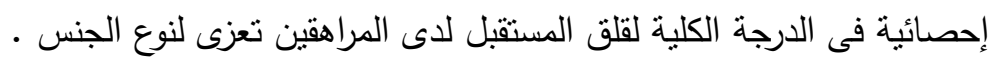

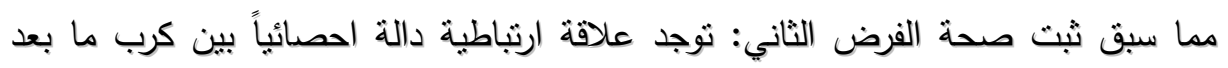

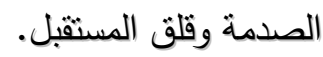

$$
\begin{aligned}
& \text { المجلد الخمسون، العدد الأول، جزء (r) يناير اب.r } \\
& \text { الترقيم الدولي 0826-0SN 1110 }
\end{aligned}
$$




\section{نتائج الفرض الثالث وتفسريها}

ينص الفرض الثالث على يوجد تأثير ذو دلالة إحصائية للمتغيرات الديموجرافية (النوع،

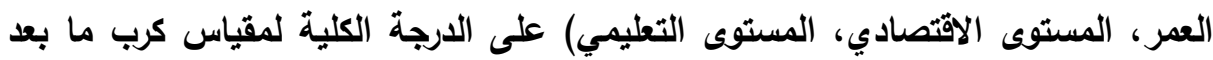

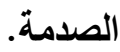
جدول (r ( ): يوضح اختبار التباين المتعدد لتوضيح نأثير للمتغيرات الديموجرافية على الدرجة الكلية لمقياس كرب ما بعد الصدمة

\begin{tabular}{|c|c|c|c|c|c|}
\hline الدلالة المعنوية & قيمة اختبار (ف) & متوسط المربعات & |درجة الحرية & مجموع المريعات & التباين \\
\hline$\cdot, \ldots 1$ & 0,107 & $r \Psi, \Lambda ו r$ & v & a) $77,79 \leq$ & المصحوذج \\
\hline$\cdot,, \ldots 1$ & $V Y \nearrow,, T \leq Y$ & Yq0Y $\leqslant, Y 1$ & 1 & Yq0Y $\varepsilon, I_{1}$ & الثابت \\
\hline$\cdot, r$ & $1, Y \mu V$ & $0, \cdot r$ & 1 & $0, \cdot r$ & النوع \\
\hline$\cdot,, \cdot 1$ & Tr,IAT & $04,7.0$ & 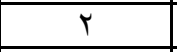 & $1 \cdot V, r)$ & العمر \\
\hline$\cdot, \cdot r$ & $r, V \varepsilon$ & $10, Y \cdot V$ & r & $r \cdot, \leqslant 1 \leqslant$ & التعليمي \\
\hline \multirow[t]{3}{*}{$\cdot, \cdot r$} & $\varepsilon, Y \cdot 1$ & $|V, \cdot N|$ & r & $r \varepsilon, 1 T r$ & الاجتماعىى \\
\hline & & $\varepsilon, .77$ & $11 \%$ & $\{00, \varepsilon \Gamma \mid$ & الخطأ \\
\hline & & & $\pi$. & $1 V \cdot \leqslant 99$ & الإجمالى \\
\hline
\end{tabular}

يتبين من نتائج الجدول السابق لاختبار التباين المتعدد وجود فروق لتأثير إحصائي عند مستوى معنوية (1 (, •) لتأثير المتغيرات الديموجرافية (العمر، المستوى التعليمي، المستوى الاجتماعي)

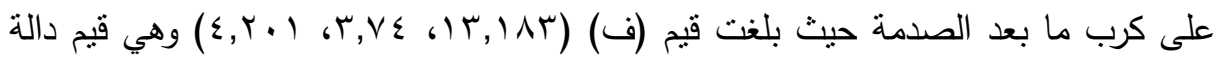
إحصائيًا عند مستوى معنوية (0. . • ) مما يشير لمعنوية النموذج لتلاك المتغيرات، وبلغت قيمة (R²)

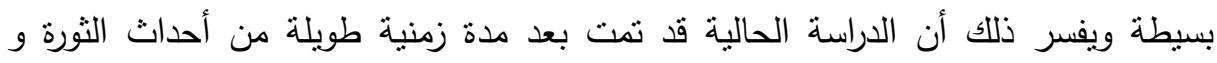

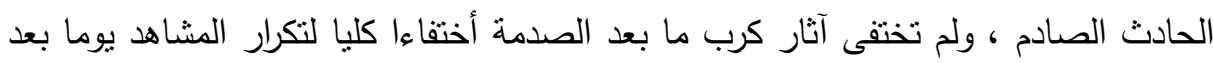

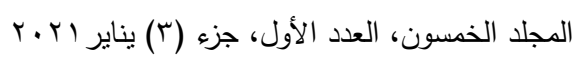


يوما وتكرار حوادث القتل و التفجير لأفراد الجيش والثرطه والأرهاب فى سيناء لذللك لم ينسى

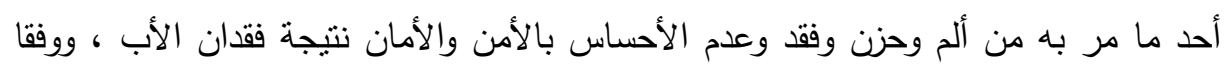

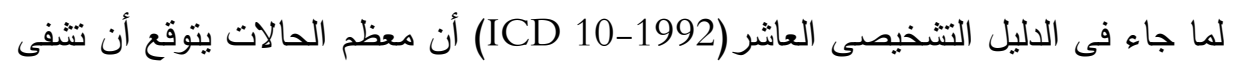

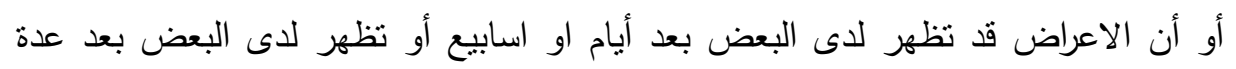

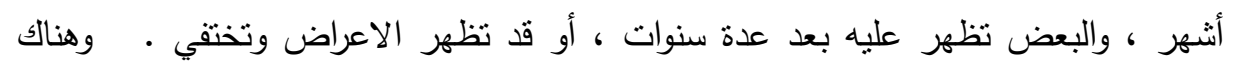

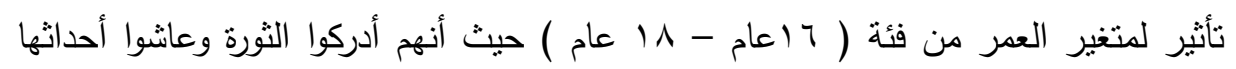

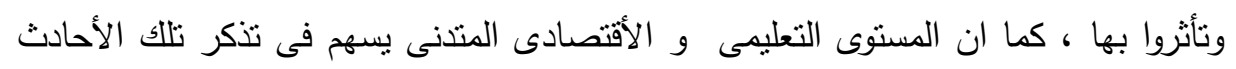

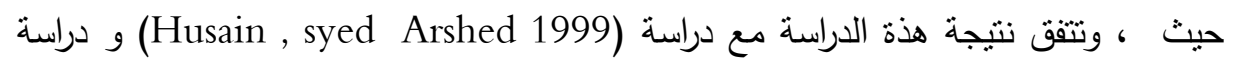

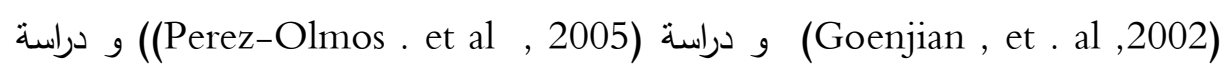

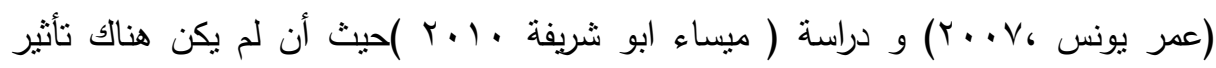

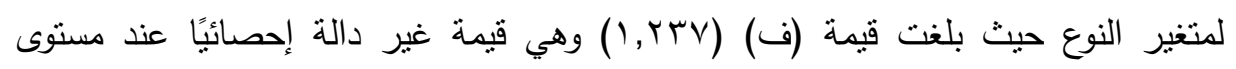
معنوية (0., •) حيث أن الجنسين عاشوا نفس الظروف السياسية و الأحداث الصادمه لئه

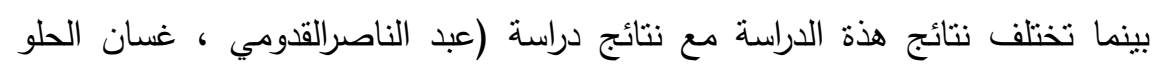

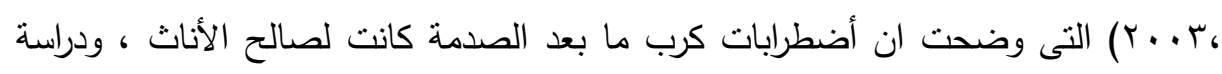

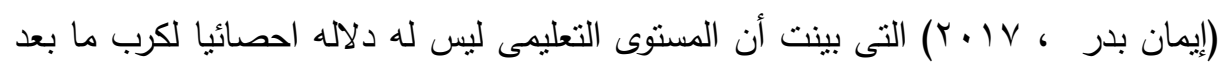

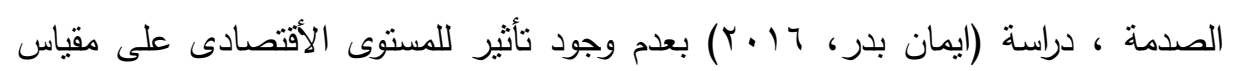
كرب ما بعد الصدمة.

مما سبق ثبت صحة الفرض الثالث جزئيًا: توجد علاقة تأثير ذو دلالة إحصائية للمتغيرات الديموجرافية (العمر، المستوى الاقتصادي، المسنوى التعليمي) على الدرجة الكلية لمقياس كرب ما بعد الصدمة.

بينما لم يثبت صحة الفرض الثالث جزئًاً: توجد علاقة نأثير ذو دلالة إحصائية لمتغيرات (النوع) على الدرجة الكلية لمقياس كرب ما بعد الصدمة.

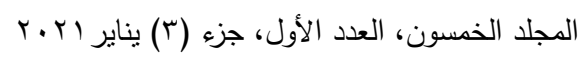

$$
\begin{aligned}
& \text { الترقيم الدولي 0826- ISSN 1110 بناير الإن }
\end{aligned}
$$


المقترحات البحثية المستقبلية:

ا. كرب ما بعد الصدمة وعلاقته بقلق المستقبل لأبناء الثهاء ، والمحرومين من البيئة

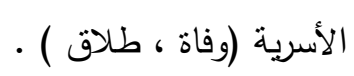

r. دراسة فاعلية برنامج إرشادي سلوكي قائم على أسلوب حل المشكلات النفسية والإجتماعية

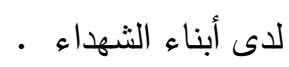

r. كرب مابعد الصدمة وعلاقته بكل من الأكتئاب والإنهاك النفسى دراسة مقارنه بين زوجات

$$
\text { الثهداء وأمهات الثهداء }
$$

ع. دراسة فاعلية برنامج علاجي قائم على حل مشكلات ما بعد الصدمة وتقليل أعراضها لدى واء

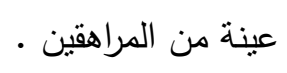

ه. الرضا عن الحياة و علاقته بمفهوم الذات لدى عينة من الأطفال المعاقين حركيا

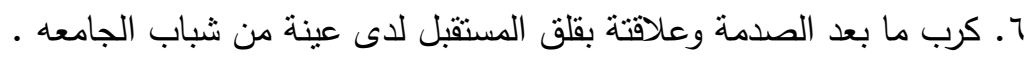

\section{هبlin}

أحمد حسن ، طلعت (0 . ب ؟) : استراتيجيات التذكر والدافعية للتعلم ومفهوم الذات كمتغيرات

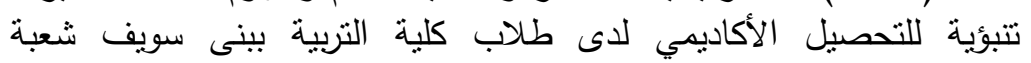
الرياضيات ـ مجلة كلية التربية ، جامعة عين شمس ، العدد(ج) الجية الجزء الثالث

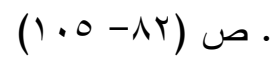

إسماعيل عبد الكريم ، محمد (Y (10) (10) : برنامج قائم على التعلم بمساعدة الاقران فى تتمية

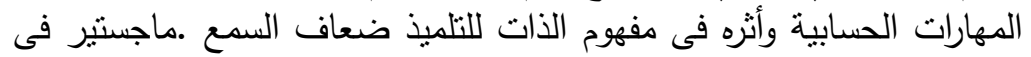

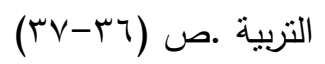

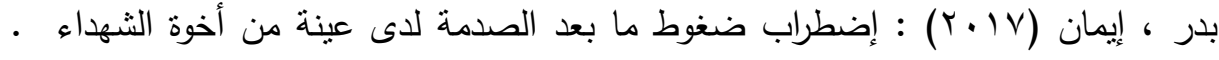

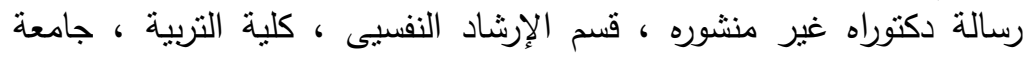

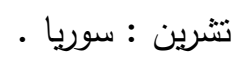

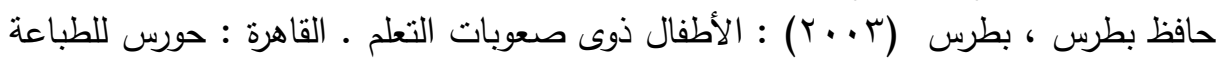

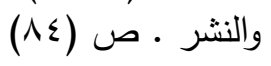

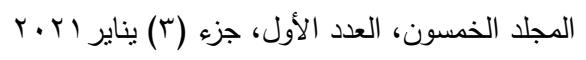

$$
\begin{aligned}
& \text { النزقيم الدولي 0826-1110 1SSN }
\end{aligned}
$$




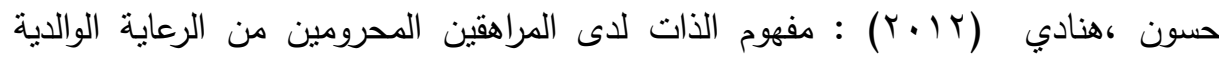

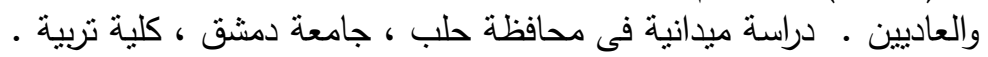

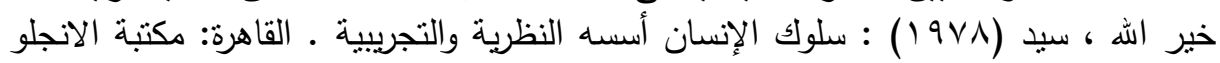

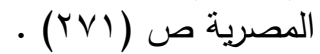

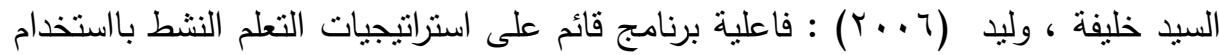

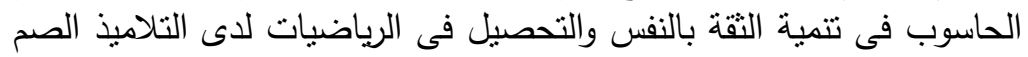

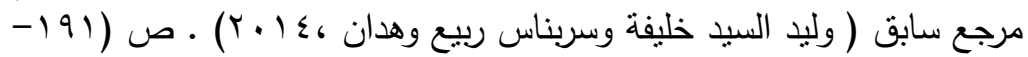
- (rVq

عبد الثـافي ، عصام: الثورات العربية الأسباب والمسارات والمآلات ـ كاتب وباحث- مصر

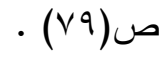

عبد الله حسيب ، عبد المنعم (1994 (199) : مستوى مفهوم الذات والتوافق النفسي وعلاقتهمـا

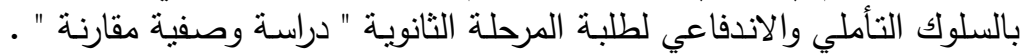

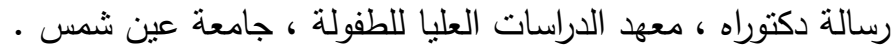

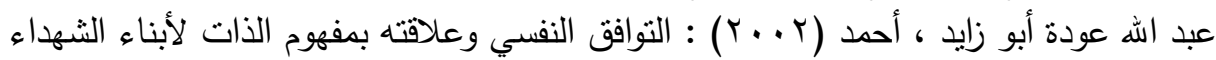

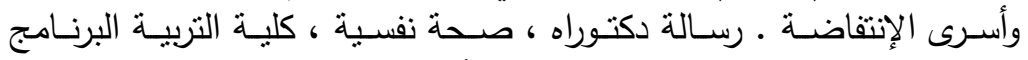

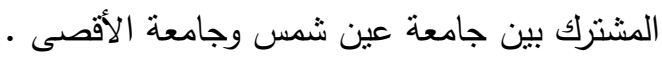

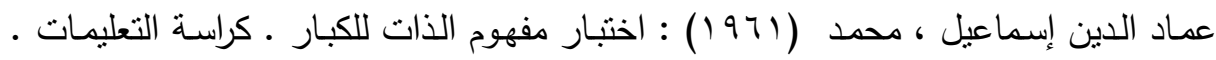

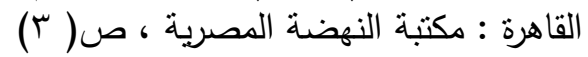

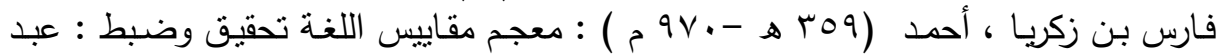

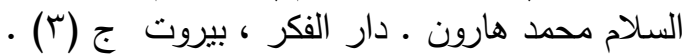

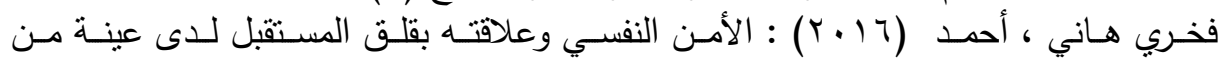

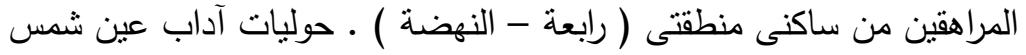

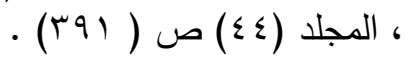

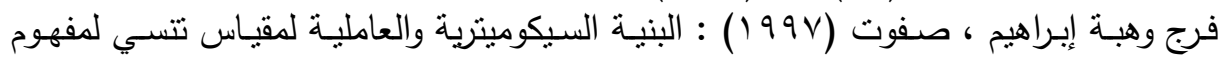

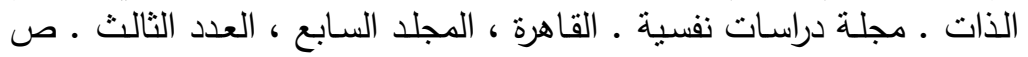

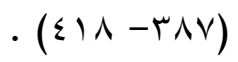

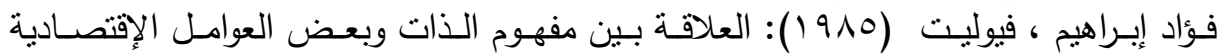

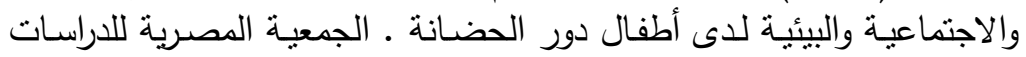

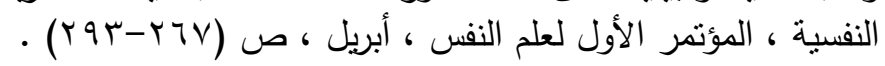

$$
\begin{aligned}
& \text { المجلد الخمسون، العدد الأول، جزء (r) يناير IT الترقيم الدولي 0826- } \\
& \text { ISSN 1110 }
\end{aligned}
$$




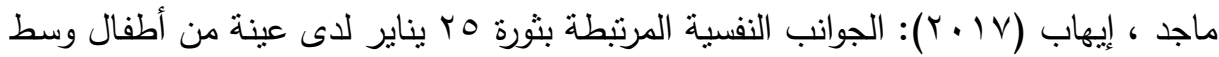

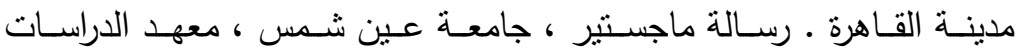

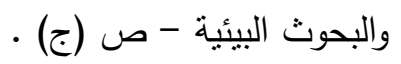

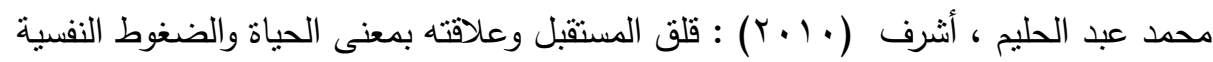

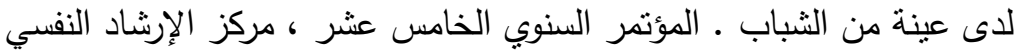

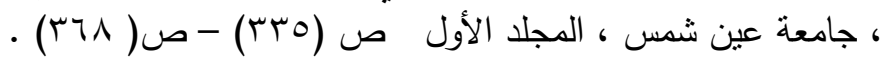

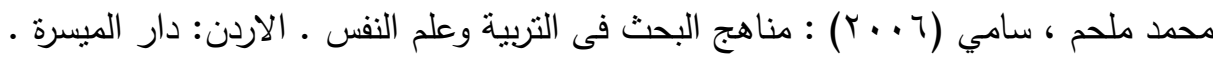

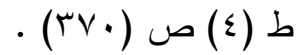

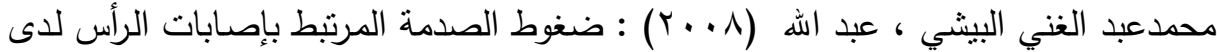

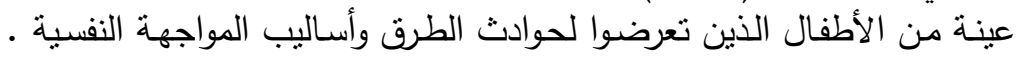

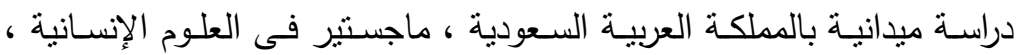

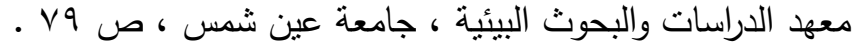

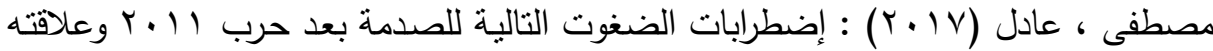

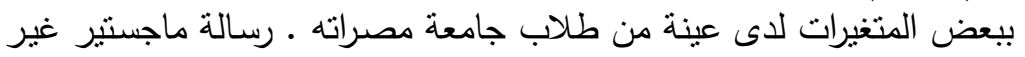

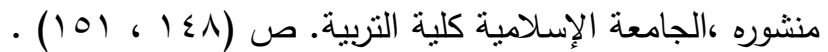

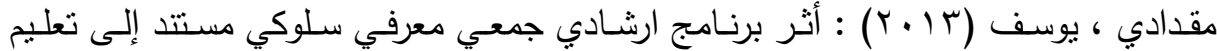

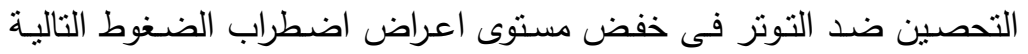

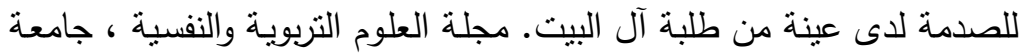

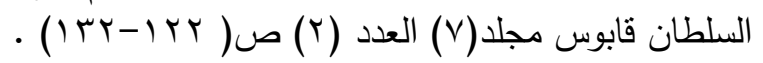

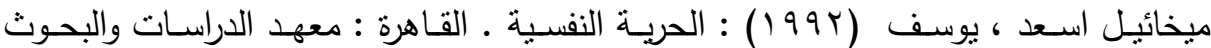

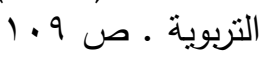

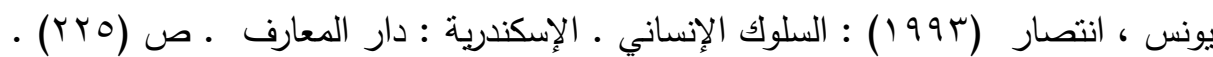
AHMAD,A (2010) : War and post-traumatic Stress Disorder in Children: A Review Health and the Environment Journal. 1 (2), (73-79) .

Bree Akesson ,(2014) : School as a place of violence and hope: Tensions of education for children and families in pastintifada , Palestine international journal of educational development available online .

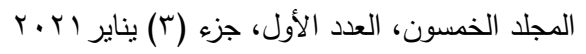

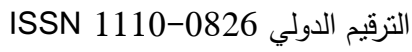




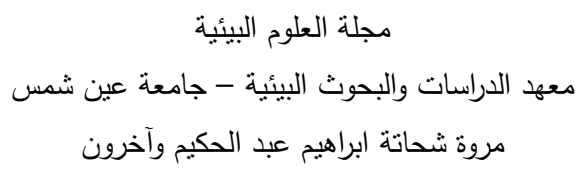

Robert R .Sears (1970) : Relation of Early Socialization Experiences to Self-concepts and Gender Role in Middle Childhood . Child Development . vol .41 ,No.2 (jun.,1970),pp.267-289.

Rogers ,M. (1978) : Social comparison in the classroom : The realationship between academic achievement and selfconsept , Journal of Educational Psychology ,70 (1) , pp (50-54)

\title{
POST-TRAUMATIC STRESS DISORDER AND ITS
} RELATIONSHIP TO SELF-CONCEPT AND FUTURE ANXIETY AMONG THE CHILDREN OF THE

\section{MARTYRS OF THE JANUARY 25 REVOLUTION}

\section{Marwa Sh. Ibrahem ${ }^{(1)}$; Gamal Shafik ${ }^{(2)}$; Farhat Alsied $^{(3)}$ and Hanan Zidane ${ }^{(4)}$}

1) Environmental Studies and Research Institute, Ain Shams University

2) Faculty of Graduate Studies for Childhood, Ain Shams University

3) The National Center for Educational Examinations and Evalution

4) Environmental Studies and Research Institute, Ain Shams University

\begin{abstract}
The study aimed to find out post-traumatic stress disorder and its relationship to self-concept and future anxiety among the children of the martyrs of the (25) January revolution, and the sample of the study consisted of (120) sons and daughters of the children of the martyrs of the (25) January revolution in Cairo governorate, whose ages ranged between (12-18) years. The study used the measurement tools

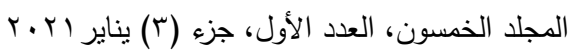

$$
\begin{aligned}
& \text { التزقيم الدولي 0826- ISSN 1110 }
\end{aligned}
$$




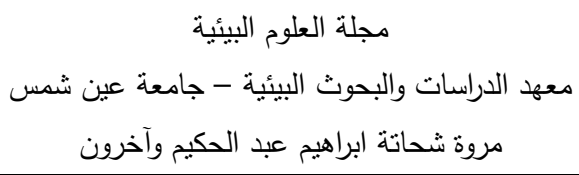

represented in three basic measures (PTSD Scale, Self-Concept Scale, and Future Anxiety Scale). The researcher used the PTSD scale prepared by the Gaza Community Mental Health Program and it consists of 19 statements.

The Self-Concept Scale Tansse, which consists of five dimensions, namely: (The first dimension: the moral self-concept scale. The second dimension: the personal self-concept scale, the third dimension: the social self-concept scale, the fourth dimension: the family self-concept scale, the fifth dimension: the criticism concept scale self.

The study used the descriptive and analytical approach in which the researcher tries to describe the phenomenon in question (post-traumatic stress disorder and its relationship to self-concept and future anxiety among the children of the martyrs of the January 25 revolution), analyzing its data and stating the relationship between its components and the opinions raised about it, and the processes involved in it. And the effects it causes, which is one of the forms of organized scientific interpretation to describe a specific phenomenon or problem and quantify it quantitatively by collecting codified data and information about the phenomenon or problem, classifying it, analyzing it and subjecting it to accurate studies

\section{The results of the study concluded:}

1. The existence of a statistically significant correlation between PTSD and self-concept.

2. The existence of a significant correlation between PTSD and future anxiety.

3. There are statistically significant differences between the means of self-concept scale scores according to demographic variables (economic level), while there are no statistically significant differences between the means of self-concept scale scores according to demographic variables (gender, age, educational level)

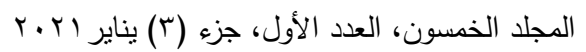

$$
\begin{aligned}
& \text { الترقيم الدولي 0826-0SN 1110 }
\end{aligned}
$$




$$
\begin{aligned}
& \text { مجلة العلوم البيئية } \\
& \text { معهد الدراسات والبحوث البيئية - جامعة عين شمس لئس البرس } \\
& \text { مروة شحاتة ابراهيم عبد الحكيم وآخرون }
\end{aligned}
$$

4. There are statistically significant differences between the mean scores of the future anxiety scale according to demographic variables (gender, age, educational level, economic level)

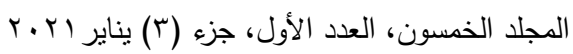

$$
\begin{aligned}
& \text { التزقيم الدولي 0826- ISSN 1110 }
\end{aligned}
$$

